\title{
NEUTRAL CLUSTER MASS SPECTROMETRY
}

\author{
Elliot R. Bernstein \\ Colorado State University \\ Department of Chemistry \\ Fort Collins, CO 80523-1872
}




\section{ABSTRACT}

The application of mass spectrometry (particularly time of flight mass spectrometry - TOFMS) to the study of neutral van der Waals and metal containing covalent clusters is discussed. In order to apply TOFMS to the study of neutral clusters, the clusters are ionized by single photon excitation or by resonance enhanced multiphoton excitation, at or near their ionization thresholds. With these techniques, neutral clusters can be accessed and explored to determine their size, structures, dynamics, reactions, ion chemistry, catalytic behavior, and electronic, vibrational, and rotational energy levels. The histories of specific central cluster species are presented to acquaint the reader with the development of neutral cluster studies since the 1980 s. Clearly only the highlights (as we see them) of neutral cluster science can be mentioned and referenced in this overview, the intent of which is to explain the roots of the field, present its evolution, and to proffer at least a few of its continuing, developing directions. 
In order for neutral clusters to be studied through mass spectrometry, the neutral clusters must first be ionized. The generation of neutral clusters in the gas phase, where they can be mass analyzed, almost always yields a rich distribution of cluster sizes and often structures. If mass spectrometry is to yield information about the properties and distribution of neutral clusters, then the neutral clusters must be gently ionized, near threshold, so that fragmentation, significant rearrangement, and internal chemistry can be kept to an absolute minimum. Threshold ionization of neutral clusters is most efficiently and effectively accomplished with a tunable ultraviolet or vacuum ultraviolet (VUV) laser, as most molecular systems have ionization energies between 6 and $16 \mathrm{eV}$. This can be accomplished by single photon ionization or a resonant one (or more) plus one (or more) photon ionization scheme. Multiphoton, non-resonant laser ionization can cause extensive fragmentation and changes in neutral cluster distribution and structure.

Given this caution, we can divide neutral clusters most studied with mass spectrometry techniques into three broad categories: small inorganic molecule clusters, such as $\left(\mathrm{H}_{2} \mathrm{O}\right)_{\mathrm{n}}$, $(\mathrm{HCOOH})_{\mathrm{n}},\left(\mathrm{SO}_{2}\right)_{\mathrm{n}},\left(\mathrm{NH}_{3}\right) \mathrm{n},\left(\mathrm{CO}_{2}\right)_{\mathrm{n}},(\mathrm{CO})_{\mathrm{n}}$ etc.; organic molecule clusters, such as, $\left(\mathrm{CH}_{3} \mathrm{OH}\right)_{\mathrm{n}}$, $\left(\mathrm{C}_{6} \mathrm{H}_{6}\right)_{\mathrm{n}},(\mathrm{RCOOH})_{\mathrm{n}},\left(\mathrm{R}^{\prime} \mathrm{OR}\right)_{\mathrm{n}},\left(\mathrm{C}_{6} \mathrm{H}_{5} \mathrm{NH}_{2}\left(\mathrm{~N}_{2}\right)_{\mathrm{n}}\right.$, etc.; and inorganic, metal clusters, such as, $\mathrm{M}_{\mathrm{m}} \mathrm{X}_{\mathrm{n}}$ $(\mathrm{X}=\mathrm{O}, \mathrm{S}, \mathrm{N}, \mathrm{C}, \mathrm{Cl}, \mathrm{H}, \ldots), \mathrm{M}_{\mathrm{m}}, \mathrm{M}_{\mathrm{m}} \mathrm{M}_{\mathrm{n}}^{\prime} \mathrm{X}_{\mathrm{y}}, \ldots$ This range of systems includes both van der Waals and covalent clusters. ${ }^{1}$

With this collection of clusters, one can study solvent effects, intra-cluster chemical reactions, intra-cluster energy and structure dynamics, cluster fragmentation, and electron distribution for neutral van der Waals molecular clusters, and cluster stability, catalytic reactions, and general cluster chemistry with neutral covalent clusters.

All these possible insights depend on mass spectrometry of these clusters, but of course not entirely on its own. First, as mentioned above, comes selective laser ionization (without 
fragmentation), employing IR, VIS, UV, VUV, and EUV (soft X-ray - SXR) lasers to learn about energy levels of clusters and prepare them for mass spectrometry through threshold single photon or resonant multi-photon ionization. This is the main application of mass spectrometry, in particular, time of flight mass spectrometry (TOFMS), to the study of neutral clusters. TOFMS is the technique of choice for study of cluster systems because ionization lasers are pulsed, the samples can be pulsed in a cold supersonic expansion, ${ }^{1,2}$ and this combination is perfect for sample conservation, the pumping system, the mass spectrometer resolution, and the mass selective access to individual clusters. What one learns from these experimental studies is the active clusters that do chemistry and that undergo some spectroscopic change. Second, one needs to generate a theoretical model for the observed behavior. We learn typically the reactants, products, and some energy levels in the original and transformed clusters, but we must as always calculate a path to discover the mechanism for the chemical transformations. The experiments tell us what clusters, processes, and reactions are important to calculate, but theory and modeling inform us about the atomic level, quantum mechanical mechanisms. Clusters are the ideal system for such a two-pronged approach because they can be experimentally identified, their energy levels can be accessed spectroscopically, and their features, chemistry, processes, dynamics, and kinetics can be presently, accurately calculated.

Thereby, neutral clusters serve as important model systems for many more complex environments and processes that cannot be isolated, identified, and calculated at the approachable level of current experimental and theoretical sophistication. Moreover, neutral clusters are interesting in and of themselves as they interface with the nano world at the size of ca. $1 \mathrm{~nm}\left(\right.$ e.g., $\left.\mathrm{M}_{5} \mathrm{O}_{10}\right)$. 


\section{MASS SPECTROMETRY OF VAN DER WAALS CLUSTERS}

Over 60 years ago Kantrowitz and Grey ${ }^{2 b}$ suggested that for the study of molecular beams, one could employ a supersonic jet rather than an effusive oven. Anderson, et al. ${ }^{2 a}$ discuss this ground breaking proposal in some detail and demonstrate the improvements that accrue from supersonic jets (nozzles) over effusive sources with regard to beam intensity and temperature. One of the early observations in these beam experiments was that condensation can occur in these high intensity, low temperature flows. This situation of course gives rise to the systematic study of van der Waals molecules and clusters through time of flight mass spectrometry. Much of the early work on small molecule van der Waals clusters was accomplished with fluorescence studies, but we will here consider and reference only mass resolved results. We will discuss and reference only a few studies that present the basic principles and benchmark examples for the importance of these cluster systems for solvation, structure, kinetics, dynamics, and reactions. By now, one could not begin to assemble a full reference list for published studies in this area.

\section{A. Solvation}

The study of solvation of a chromophore (like, $\mathrm{I}_{2}, \mathrm{NO}_{2}$, benzene, and others) by various solvents (not spectroscopically active species) such as $\mathrm{He}, \mathrm{CH}_{4}, \mathrm{C}_{\mathrm{n}} \mathrm{H}_{2 \mathrm{n}+2}, \mathrm{H}_{2} \mathrm{O}, \mathrm{NH}_{3}, \ldots$ was initially accomplished in supersonic beam experiments in the Levy and Wharton laboratories in the mid 1970 's ${ }^{2 \mathrm{c}}$ through fluorescence excitation techniques. Mass spectrometry techniques were first applied to these systems shortly after the initial studies by the Smalley group. ${ }^{2 \mathrm{~d}, \mathrm{e}}$ To see the power of this latter approach, the study of aniline $(\mathrm{He})_{\mathrm{x}}(\mathrm{x}=1,2,3)$ clusters can be reviewed. ${ }^{3}$

The aniline absorption feature FWHM in these mass resolved spectra for the $0_{0}^{0}(\tilde{\mathrm{A}} \leftarrow \mathrm{X})$ transition time of flight 2-color mass spectra is ca. $3 \mathrm{~cm}^{-1}$ (mostly residual rotational structure for 
the expansion sample of aniline/He). The aniline $(\mathrm{He})_{1,2}$ cluster spectra both have sharper features (ca. $2 \mathrm{~cm}^{-1}$ ), as detected in the appropriate mass channel, that are red shifted only within the line width of the aniline feature. Such solvation studies would not be possible without mass resolved excitation spectra: spectra of aniline $(\mathrm{He})_{3}$ are in this context broad $\left(7.5 \mathrm{~cm}^{-1}\right)$, weak, and only detected in the aniline $(\mathrm{He})_{3}$ mass channel. The structure of these clusters, at the time based on potential energy calculations, is best described as having the He above and below the aniline ring, interacting with the $\pi$-electron system, displaced somewhat toward the $\mathrm{NH}_{2}$ ring substituent.

The study of the solvation of benzene by small hydrocarbons is instructive with regard to cluster structure and the nature of the solvation process. ${ }^{4}$ Consider first the benzene $\left(\mathrm{CH}_{4}\right)_{1,2,3}$ clusters: due to benzene's high symmetry $\left(\mathrm{D}_{6 \mathrm{~h}}\right)$, the ${ }^{1} \mathrm{~B}_{2 \mathrm{u}} \neg{ }^{1} \mathrm{~A}_{1 \mathrm{~g}}$ first excited singlet transition is forbidden and the $0_{0}^{0}$ origin is not observed for either the benzene molecule or benzene $\left(\mathrm{CH}_{4}\right)_{1}$ and one of the benzene $\left(\mathrm{CH}_{4}\right)_{2}$ isomers. In these latter structures the 6-fold axis of benzene is preserved if the methane resides on the original 6-fold axis; however, the benzene $\left(\mathrm{CH}_{4}\right)_{2}$ structure, with both methanes on the same side of the benzene ring, is of low symmetry and thus for this structure the $0_{0}^{0}$ transition is observed. As can be imagined, the situation becomes more complicated as the alkane solvent molecules become more structured. Solvation structure, and thereby spectra, become further complicated as both solute and solvent are expanded to include lower symmetry systems with more than one bonding site. One can see how the spread of the system spectrum with many small cluster isomers will generate a composite, inhomogeneous spectrum for a solution of the chromophore in a given solvent. Nonetheless, one must additionally understand the difference between a large cluster and a solution with regard to an extrapolation from one set of data to another. For example, a solution of benzene in methane or 
propane will never be completely explained or modeled by a large cluster of benzene(solvent) $\mathrm{n}>50$ perhaps, because solvation will not occur for this cluster at the C-H plane. Again, for benzene $\left(\mathrm{H}_{2} \mathrm{O}\right)_{n}$ clusters, one can expect that only one side of the benzene ring will be solvated (e.g., the benzene would rest on water drop).

With benzene such a good solute probe species, and water such an important solvent, one is not surprised to find the benzene $\left(\mathrm{H}_{2} \mathrm{O}\right)_{n},(n=1, \ldots, 12)$, clusters have a long history of study. ${ }^{7}$ This system points to some of the difficulties associated with TOFMS of van der Waals clusters. The clusters can fragment upon ionization and spectroscopic features belonging to $\mathrm{C}_{6} \mathrm{H}_{6}\left(\mathrm{H}_{2} \mathrm{O}\right)_{\mathrm{x}}$ can be formed in the $\mathrm{C}_{6} \mathrm{H}_{6}\left(\mathrm{H}_{2} \mathrm{O}\right)_{\mathrm{x}-\mathrm{a}}$ mass channel, due to non-threshold ionization and/or internal cluster chemistry and relaxation upon even the lowest possible (vertical) energy ionization. Such fragmentations can occur through unavoidable chemical reaction in the solute ${ }^{+}(\text {solvent })_{\mathrm{x}}$ cluster: proton and electron transfers are examples of ionization induced reactions in solute/solvent clusters and will be discussed separately below. After a series of studies on benzene/water clusters, ${ }^{5} \mathrm{C}_{6} \mathrm{H}_{6}\left(\mathrm{H}_{2} \mathrm{O}\right)_{1}$ has a hydrogen bonding orientation such that the $\mathrm{O}$ atom of water is more or less centered over the aromatic benzene ring and the hydrogen atoms are coordinated to the ring, but the $\mathrm{O}-\mathrm{H}$ bonds are not perpendicular to it. Further, additional water molecules are coordinated to the first water and not the benzene directly, as might be expected. This structure for $\mathrm{C}_{6} \mathrm{H}_{6}\left(\mathrm{H}_{2} \mathrm{O}\right)_{1}$ is not rigid, as will be discussed below for this and other aromatic/small molecule clusters.

Many more clusters have of course been studied throughout the 1990's and into the 2000's, and will continue to be. In particular, the trend in Physics and Chemistry in the past 20 years has been to employ more and more sophisticated multi-resonance spectroscopic techniques (e.g., IR/UV, IR/VUV, IR/EUV, Raman, coherent approaches, etc.), all TOFMS detected and/or 
selected, and apply these approaches to more and more complicated systems (e.g., biological, in particular). Thus, porphyrins, ${ }^{6}$ phthalocyanines, ${ }^{7}$ nucleic acid bases, ${ }^{8}$ nucleosides,${ }^{9}$ sugars, ${ }^{9}$ amino acids and peptides, ${ }^{9-12}$ and many more have been accessed, identified, clustered and solvated to determine their isolated molecule behavior and solvation effects and changes. In this retrospective and prospective, one cannot cover all that has been done: we are just able to point to the large volume of solute/solvent spectroscopic cluster studies that have been pursued through mass selection and detection. These newer directions have been rewarding from the point of view of biological molecule structural rearrangements and higher order structure for both peptides and DNA base related systems. The study of neurotransmitter molecules (based on the phenethylamine and catachol like structures) and drug based systems such as methamphetamines have become prevalent. ${ }^{13}$ These trends seem to be growing as new physical techniques become available and theoretical approaches expand to analyze complicated data sets for large molecules. TOFMS for selection and detection of clusters also enables other techniques to be employed for the study of inhomogeneous samples such as clusters. One such application is to negative ion photoelectron spectroscopy by which technique negatively charged clusters (e.g., $\left.\left(\mathrm{H}_{2} \mathrm{O}\right)_{\mathrm{n}}^{-}\right)$are sorted in a TOFMS arrangement and the laser detached electron is analyzed for information about the ground state neutral cluster. ${ }^{14}$ Note that for the most part vdW clusters are not rigid. ${ }^{15}$ For example, the benzene dimer components can have many rotational axes depending on the dimer's structure, and benzene $\left(\mathrm{CO}_{2}\right),\left(\mathrm{N}_{2}\right),\left(\mathrm{H}_{2} \mathrm{O}\right)$, etc. clusters can have internal rotational axes for the small molecule solute species. These semi-free rotational levels can lead to quite complex van der Waals mode transitions built on the benzene molecule vibronic transitions. A proper way to deal with the symmetry of such non-rigid systems is covered in ref. 16. 
Before leaving this section of neutral cluster solvation structure, three more systems should be mentioned to show the range of capabilities these spectroscopic/mass spectrometry techniques can display. We want to address cluster studies for radicals, Rydberg states, and their solute/solvent clusters.

Radicals are generated by many chemical reactions and are implicated in a number of reaction mechanisms, in both the gas phase and in solution. Thereby, the study of radicals isolated in a supersonic expansion and solvated in clusters is a well-founded area for mass selected and detected radical species. ${ }^{15 a, 17}$ Radicals generated in this manner include benzyl, cyclopentadienyls (cpds), methoxy, NCO, and others. These radicals can be generated by photolysis at the nozzle throat or in a high-pressure $(1-10$ torr) reaction tube following the nozzle, but prior to the supersonic expansion into the vacuum system. Solvation causes both blue and red shifts of the radical transitions observed, depending on the structure of the radical/solvent clusters and the nature of the electronic transition. The generation of particular radicals in the gas phase and their cluster formation can be employed to prove proposed reaction mechanisms in solution. Trapping such species in the gas phase can be a demonstration of their existence: a negative example here can be mentioned for the long sought after phenylnitrene radical. ${ }^{17 a}$ Note that in this instance one can identify the putative radical through its resolved spectra (both mass and absorption) rather than guess at its presence from broad solution phase spectra. Appropriate clusters can also stabilize a reaction intermediate so that it can be identified and a reaction mechanism can be determined.

One advantage of cold, gas phase, isolated molecule, mass selected/and detected spectroscopy is that one can observe and resolve spectra of transitions that are very sensitive to intermolecular pertubations. Many Rydberg transistions ( $n=2$ to $n=3$ shells) of organic systems 
(first row atoms, B, .., F) fall into this category. Moreover, careful gas phase solvation studies of such systems (e.g., different cluster binding sites and sizes) can allow the mapping of the excited Rydberg state electronic distribution. ${ }^{18}$ Examples of such studies can be found for azabicyclooctane (ABCO, $\mathrm{C}_{7} \mathrm{H}_{13} \mathrm{~N}$ ), diazabicyclooctane (DABCO, $\mathrm{C}_{6} \mathrm{H}_{12} \mathrm{~N}_{2}$ ), hexamethylene tetramine (HMT, $\left.\mathrm{C}_{6} \mathrm{H}_{12} \mathrm{~N}_{4}\right)$, dioxane $\left(\mathrm{C}_{4} \mathrm{H}_{8} \mathrm{O}_{2}\right)$, and others. Through cluster structure studies one can map the distribution of the Rydberg excited state and thereby determine its nature and how solvation influences excited state electronic and vibronic properties and kinetics (e.g., lifetimes, intersystem crossing, internal conversion, and potential energy surface interactions).

No discussion of van der Waals cluster structure and properties would be complete without at least a few words about van der Waals solute dimers. While the possibilities of such clusters are virtually limitless, one must admit that the benzene dimer structure and properties are issues of long standing and still of current interest and research. ${ }^{19}$ We reference only a few key recent papers that refer to most of the earlier work. Early unpublished electronic spectra of the benzene dimer $\left(\mathrm{C}_{6} \mathrm{H}_{6}\right)_{2}$ in a $\sim 99.9 \% \mathrm{C}_{6} \mathrm{D}_{6} / 0.1 \% \mathrm{C}_{6} \mathrm{H}_{6}$ crystal at $1.3 \mathrm{~K}$ were obtained but not interpreted due to a 4 molecule/unit cell crystal structure (many different possible dimer geometries) and interference from ${ }^{13} \mathrm{CC}_{5} \mathrm{H}_{6}$ and possibly ${ }^{13} \mathrm{C}_{2} \mathrm{C}_{4} \mathrm{H}_{6}$ features surrounding the $\mathrm{C}_{6} \mathrm{H}_{6}$ monomer transition. Molecular beam electric resonance studies (Klemperer, et al.) suggest the dimer has a "T" shaped structure. Later electronic spectra suggest parallel displaced and tilted T (t-T) structures, but IR, Raman, $\mu$-wave spectra have now settled on a t-T structure. Theory, in the form of single reference state quantum mechanical calculations, is not much help, even now, for getting the right structure, as all three structures have calculated energies within ca. 1 $\mathrm{kcal} / \mathrm{mol}$ of each other. Both theory and experiment suggest the dimer is not rigid. The dimer does not fluoresce, and the $S_{1}$ state might be a charge transfer state with a parallel displaced 
structure, while $\mathrm{S}_{0}$ has a $\mathrm{t}-\mathrm{T}$ structure. If this were true, a multi reference approach to theory static and dynamic correlation, (e.g., CASSCF and CASSCF/MP2), employing a large basis set with diffuse functions, might yield a better overall picture of the structure and dynamics of the benzene dimer. This system is a benchmark and a test-bed for aromatic $\pi-\pi$ interactions and dispersion, so the quest for definitive results continues.

\section{B. Energy dynamics and kinetics: intracluster vibrational energy redistribution (IVR) and vibrational predissociation (VP)}

Following the excitation of a molecule to a vibronic state (e.g., $\left.S_{1} v\right)$, the excitation energy can redistribute within the molecule, such that the molecule can find itself in $S_{1} v_{b} \ldots v_{c}, T_{a} v_{b} \ldots, v_{c}$, $\mathrm{S}_{0} \mathrm{v}_{\mathrm{a}} \ldots \mathrm{v}_{\mathrm{g}}$, etc. Under the constraint that for an isolated molecule energy is conserved, these transitions would be recognized as general IVR: the "optically active" state "relaxing" to "dark" states. The excited molecule can of course also emit a photon from the initially state $S_{1} v_{x}$ or from another state in $S_{1}$, say $S_{1} v_{y} \ldots v_{z}$, depending on the molecular properties, in particular the density of other $S_{1} v_{n}$ excited states in "resonance" with the initial $S_{1} v_{x}$ excited states accessed. All these possibilities are well known, ${ }^{20}$ and we are assuming here in this description that the molecule is not photochemically active in $S_{1}($ e.g., benzene, toluene, aniline,...) and that the various potential energy surfaces are more or less uncoupled and independent. This situation should be well characterized by Fermi's Golden Rule and by RRKM theory ${ }^{21}$ : the density of (dark) states at the $\mathrm{S}_{1} \mathrm{~V}_{\mathrm{x}}$ energy should be one of the controlling factors in the redistribution of the initial excitation, along with the size of the coupling matrix elements between the initially excited (light) state and numerous dark states.

In a van der Waals cluster the dark states now include the intermolecular modes built on the various electronic and vibronic molecular states. Thus, in addition to the molecular energy 
dynamics, the cluster can undergo a serial redistribution of energy from the molecular states to the cluster states $\left(\mathrm{S}_{1} \mathrm{v}_{\mathrm{i}}\right.$ plus vdW modes) (IVR), and from these intermolecular modes the clusters can vibrationally predissociate (VP). Such transitions can be modeled by statistical theory, given by Fermi's Golden Rule and RRKM theory, and can be measured experimentally with van der Waals clusters aniline $(\mathrm{Ar})_{1},\left(\mathrm{~N}_{2}\right)$, and $\left(\mathrm{CH}_{4}\right)_{1} \cdot{ }^{4,22}$ While most of these dynamical and kinetics studies are accomplished through emission studies, without TOFMS to identify and prove the species studied are as assumed, the details of the assignments and spectral identifications would not be substantiated in these complicated spectra. The basic idea is the following: 1. a van der Waals cluster is excited to its $S_{1} v_{x}$ state; 2. it undergoes IVR to yield a lower energy $S_{1}$ vibrational state and generate excited vdW modes to conserve energy; 3 . if the energy in the $\mathrm{vdW}$ modes is greater than the cluster binding energy, the cluster can dissociate in a statistical mechanism, as IVR amongst the vdW modes (due to the various anharmonic couplings) is very fast. Thus we find that IVR and VP demonstrate opposite trends. For the aniline( $(\mathrm{Ar})_{1}$ cluster, IVR from aniline to the vdW modes is slow because the vdW density of states is small; however, the IVR in the vdW modes is fast(er) and the low density of states yields a very fast statistical VP. For aniline $\left(\mathrm{N}_{2}\right)_{1}$ the density of vdW states is larger and this yields a faster IVR and a slower VP. For aniline $\left(\mathrm{CH}_{4}\right)_{1}$ now IVR from aniline to the vdW modes is rapid due to the high vdW density of states, and VP is slow because of this high density of states and the statistical nature of the process. As a final demonstration of the statistical nature of these events and support for the importance of density of states (Fermi's Golden Rule and RRKM theory) for these kinetics and dynamics, aniline with a hydrocarbon tail (4-ethylaniline) and thus low energy modes is clustered with $(\mathrm{Ar})_{1},\left(\mathrm{~N}_{2}\right)_{1}$, and $\left(\mathrm{CH}_{4}\right)_{1}$. A statistical interpretation of these kinetics and product state distributions demonstrates that all low energy modes are important for cluster vibrational 
energy flow for aromatic/polyatomic clusters in which $\mathrm{k}_{\mathrm{IVR}}>>\mathrm{k}_{\mathrm{VP}}$. For 4-ethylaniline $(\mathrm{Ar})_{1}$, $\mathrm{k}_{\mathrm{VP}}>\mathrm{k}_{\mathrm{IVR}}$ and a statistical distribution of energy among the chromophore and van der Waals modes is not achieved. The central determining factor for the vibrational dynamics of these clusters is overall density of low energy modes. These findings give one insight into noncoherent vibrational dynamics in both gas and condensed phases.

\section{Reactions}

We continue this retrospective on neutral van der Waals clusters with the study of chemical reactions. Within this rubric we give examples of proton and electron transfer reactions, hydrogen bonding changes with electronic excitation, ionic reactions following even threshold ionization, and radical reactions.

The simplest cluster reaction can be thought of as an intermolecular electron transfer, as for example for 4-(N,N-dimethylamino)benzonitrile (DMABN) solvated with up to 5 acetonitrile molecules. The general idea here is that DMABN has a first excited $S_{1}$ state that is $\pi-\pi$ in nature. Solvated with $\mathrm{H}_{2} \mathrm{O}$, the $\left(\mathrm{CH}_{3}\right)_{2} \mathrm{~N}$ - and $-\mathrm{CN}$ groups are locally coordinated with little effect on the nature of the $\mathrm{S}_{1}$ state. Solvated at the aromatic ring with $\mathrm{CH}_{3} \mathrm{CN}$ molecules, the $\mathrm{S}_{1}$ state becomes $\mathrm{a}\left(\mathrm{CH}_{3}\right)_{2} \mathrm{~N}-$ to $-\mathrm{CN}$ charge transfer state. ${ }^{23}$

Proton transfer reactions can occur in van der Waals clusters for the proper solvents and extent of solvation. Proton transfer is generated by electronic excitation (naphthol or phenol $\left.\left(\mathrm{NH}_{3}\right)_{\mathrm{n}}\right)$ or by ionization (toluene $\left.\left(\mathrm{NH}_{3}\right)_{\mathrm{n}}\right)$. The $\mathrm{pK}_{\mathrm{a}}\left(\mathrm{S}_{1}\right.$, or $\left.\mathrm{I}^{+}\right)$must be $>\mathrm{pK}_{\mathrm{a}}\left(\mathrm{S}_{0}\right)$ for such reactions to occur. ${ }^{22 c, 24}$ These studies show that important factors for such reactions are the solvation of both the proton and the neutral radical (e.g., benzyl and $\mathrm{NH}_{4}{ }^{+}$) and the vibrational excitation energy generated in the cluster even at threshold ionization. Many variations on these clusters exist, for example, for 7 -azaindole, ${ }^{25}$ DNA- like base molecules, ${ }^{8}$ and others. 
Suggestions have been made that for some neutral excited state clusters the $\mathrm{H}^{+}$transfer can actually be a $\mathrm{H}^{0}$ transfer: ${ }^{26}$ this is apparently still an open question and is of course system dependent.

An example of radical reactions in solute/solvent organic clusters can be mentioned for the solvation of the benzyl radical with alkenes. ${ }^{27}$ Benzyl $\left(\mathrm{C}_{2} \mathrm{H}_{4}\right)_{1,2}$ spectra ionization energy, and lifetimes are very different than those for benzyl $\left(\mathrm{C}_{2} \mathrm{H}_{6}\right)_{1,2}$. This is attributed to reactivity of the radical not in its ground state but in its excited state. This represents a structural approach to bimolecular (and higher) radical chemistry.

Advances in many areas of chemical physics open new areas for reactivity research with neutral clusters. Such new approaches involve laser advances (VUV, EUV, IR, non-linear techniques), ionic detection advances (imaging in general), improved mass spectrometry techniques (reflection TOFMS, and different sample generation techniques (laser ablation, electrospray, discharge, etc.). Because of such advances we can now access pure solute clusters, such as $\left(\mathrm{CO}_{2}\right)_{\mathrm{n}},\left(\mathrm{SO}_{2}\right)_{3},\left(\mathrm{H}_{2} \mathrm{O}\right)_{\mathrm{n}},\left(\mathrm{NH}_{3}\right)_{\mathrm{n}},\left(\mathrm{CH}_{3} \mathrm{OH}\right)_{\mathrm{n}},(\mathrm{RCOOH})_{\mathrm{n}}$ and mixed clusters of these systems with $\left(\mathrm{H}_{2} \mathrm{O}\right)_{\mathrm{m}} \cdot{ }^{28}$ Solutes no longer require an intermediate $\mathrm{S}_{\mathrm{n}}$ transition to enable near threshold, nonfragmenting ionization: since the implementation of techniques involving VUV, EUV, and IR plus VUV and EUV excitations, many more important van der Waals and hydrogen bonded species are available for access. This enables study of solute/solute and solute/solvent neutral clusters and their ion states, dynamics, and reactions, for such important systems as sugars, amino acids, peptides, $\alpha, \beta, \gamma$ - substituted acids, etc. ${ }^{8,911,28}$ The general observations here yield ion, fragmentation, and atom transfer reactions. Apparently, as long as the ionization is by a single photon, the photoelectron removes much of the excess ionization energy (above the vertical - adiabatic ion ionization difference) as kinetic energy, as could be 
anticipated based on photoelectron spectroscopy. ${ }^{14}$ The details of this chemistry and structural data can be found in ref. 29 and they depend on specific structures, interactions, and reactions for each system. Structural calculations for these clusters are of central importance, and reactions and especially stable cluster sizes are found for these clusters.

\section{Current and Future Directions and Efforts}

The above retrospective on neutral van der Waals clusters, addressed through mass spectrometry, should serve as a basis for integrating new chemical physics techniques and ideas with TOFMS and RTOFMS to study such systems as discussed above, as well as new ones now made accessible through experimental and theoretical advances. Thus, current studies of clusters with tunable VUV lasers, ${ }^{28}$ and EUV lasers, ${ }^{29}$ fs and as lasers for ionization and ablation, generate new kinetic and dynamic insight into the behavior of neutral clusters through single photon and multiphoton (intermediate state) ionization to determine reaction mechanisms and product energy distributions. Such studies are routine for neutral molecules at present and should be possible for clusters, as well.

One of the difficulties of working with neutral clusters is that most generated gas phase cluster samples are not homogeneous. In many instances this situation can confuse the identification of, and the nature of, the chemistry detected for each cluster. One way to circumvent this problem is to generate negative ion clusters, sort them in a TOFMS apparatus, and then remove the excess electron through threshold photodetachment. One then has mass selected neutral clusters for whatever spectroscopic studies are of interest. Such a report has appeared for $\mathrm{Cu}$ atoms and $\mathrm{Ag}_{3}$ clusters about 10 years ago. ${ }^{30}$

A current trend in chemistry is to apply spectroscopic techniques to the study of model biological systems: amino acids, peptides, saccharides, nucleobases, nucleotides, and 
nucleosides. ${ }^{9,28}$ The ions of saccharides are not stable and a number of fragmentation pathways are open to generate many different ions. Sugar molecules are incorporated into both proteins and nucleic acids and their resistance to ionizing radiation in these systems is of considerable interest. In nucleotides, the carbohydrate nucleobase bond is the one that breaks under VUV irradiation. ${ }^{9}$ Clearly further experiments and theory need to be pursued for these systems to elucidate and explicate this behavior.

We have not discussed the exceedingly important area of coherent spectroscopy and coherent dynamics in clusters. Fs and as laser techniques are an important continuing and new direction for the study of vdW clusters. ${ }^{31}$

\section{NEUTRAL COVALENT CLUSTERS}

With the pioneering work on covalent clusters by Smalley and coworkers ${ }^{32}$ in the early 1980 's, the systematic study of covalent metal containing, and inorganic clusters in general, began. The initial effort in this research was to determine cluster size and structure. Cluster size is a straightforward measurement for cluster ions: their structure is calculated by many different levels of theory, from density functional theory (DFT) to coupled cluster theory (e.g., $\operatorname{CCSDC}(\mathrm{T}))$. Neutral clusters face the problem of cluster ionization in order to employ mass detection techniques: if one wants to learn the stable distribution of neutral clusters for a particular generation process such as laser ablation, for example in order to employ the cluster beam for reaction studies, one must find a non-destructive, non-fragmenting ionization method. ${ }^{32,33}$ For van der Waals solute/solvent systems the solute can be chosen with an intermediate $S_{1}$ resonance state that is high enough in energy such that a one plus one resonance enhanced multiphoton ionization (REMPI) can be arranged near threshold ionization: fragmentation is thereby greatly suppressed or eliminated. For covalent $M_{a} X_{b}$ or $M_{n}$ clusters the 
density of excited electronic and vibronic states is generally so high the multiphoton absorption and ionization are the rule rather than the exception. This process usually leads to many photon absorption, and finally cluster fragmentation: with cluster fragmentation, one loses information on the neutral cluster distribution. Given this situation, one does not know the neutral cluster distribution, the stable neutral clusters for the cluster synthesis conditions, nor the neutral cluster reactants in a cluster reaction study. Apparently, due to the almost continuous strong absorption of covalent inorganic clusters throughout the visible, ultraviolet, and vacuum ultraviolet regions, these clusters can absorb many photons on the nanosecond time scale. Photons with less energy than a cluster adiabatic ionization energy (AIE) are thereby absorbed for the neutral and ion, causing cluster fragmentation from both preionized and ionized clusters. If, on the other hand, a high energy photon with $\left(\mathrm{E}_{\mathrm{ph}}-\mathrm{VIE}\right)>0$ ionizes the clusters and the photon density is low, $\leq$ $10^{12}$ photons / ns pulse $(<10 \mu \mathrm{J} /$ pulse $)$, the clusters do not fragment and most of the excess energy above the ionization threshold is removed by the electron in the form of electron kinetic energy. Based on the success of photoelectron spectroscopy (PES), this is to be expected. These phenomena have been demonstrated over a number years; ${ }^{34}$ low pulse energy, $1-10 \mathrm{~ns}$ pulses, with photon energies $\sim 10 \mathrm{eV}$ and over, are typical conditions that ionize neutral inorganic clusters without fragmentation. Thereby, mass spectrometry techniques can be used to study neutral cluster distribution, neutral cluster reactions, and the role of neutral clusters or sites in catalytic chemistry. Figure 1 gives a typical set of schematic pictures and a typical experimental laser ablation based TOFMS, modeled after the early pioneering studies of the Smalley group. ${ }^{1,2}$

\section{A. Covalent Cluster Stoichiometry and Structure}

Single photon ionization of neutral covalent metal oxide clusters with 10.5 and 26.5 $\mathrm{eV} /$ photon at low energy/pulse $(1-10 \mu \mathrm{J})$, can give the neutral cluster distribution without 
fragmentation. ${ }^{33,35}$ This fact has been demonstrated through comparisons with $\mathrm{Zn}_{m} \mathrm{O}_{\mathrm{n}}, \mathrm{Fe}_{\mathrm{m}} \mathrm{O}_{\mathrm{n}}$, $\mathrm{V}_{\mathrm{m}} \mathrm{O}_{\mathrm{n}}, \mathrm{Cu}_{\mathrm{m}} \mathrm{O}_{\mathrm{n}}, \mathrm{Ti}_{\mathrm{m}} \mathrm{O}_{\mathrm{n}}$ samples and others. The mass spectra for $\mathrm{Ta}_{\mathrm{m}}, \mathrm{Ta}_{\mathrm{m}} \mathrm{O}_{\mathrm{n}}, \mathrm{Nb}_{\mathrm{m}} \mathrm{O}_{\mathrm{n}}$, and $\mathrm{V}_{\mathrm{m}} \mathrm{O}_{\mathrm{n}}$ at different photon energies up to $26.5 \mathrm{eV}$ are particularly compelling concerning the usefulness and importance of single photon ionization: under these conditions such clusters as $\mathrm{V}_{2} \mathrm{O}_{5} \mathrm{H}$ and $\mathrm{V}_{2} \mathrm{O}_{5} \mathrm{H}_{2}$ can be detected and characterized.

Once the appropriate neutral cluster storchiometries are known from reliable SPI TOFMS, calculations can be undertaken to determine cluster or "molecular" structure. A complete picture then emerges for the "molecular" properties of these new inorganic species.

Clearly for general clusters of oxides, carbides, nitrides, borides, sulfides of various metals, density functional theory (DFT) is the only consistent and broadly applicable approach. MP2, and in some cases, CC theory at various levels can be used to improve an initial survey calculation, but only for specific and special structures on a given electronic state potential energy surface.

The choice of functional and basis set for a DFT structure or reaction surface calculation is not always obvious. One must calculate some experimentally known system in order to be sure that the correct results are possible. For example, if a structure contains V-O, V-V, O-O, etc. bonds, the choice of functional and basis set must be tested against the $\mathrm{X}-\mathrm{Y}$ and $\mathrm{Y}-\mathrm{X}-\mathrm{Y}$, etc. bond energies, distances, and angles (if known) to obtain the correct reactants, products, barriers and intermediates for structures, vibrations, and electronic states. ${ }^{35}$ (See Figure 2.)

Studies of main group clusters prior to $~ 1990$ are reviewed by Mandich et al. ${ }^{32 b}$ for both neutral and ionic species with regard to distributions and chemical reactions. The number of systems covered for this early work shows the great interest in the behavior of covalent systems 
in general. Early work on neutral metal clusters and metal compound systems employing multiphoton ionization can be found in references 32 and 34.

The techniques of SPI, TOFMS, and laser ablation have enabled new species to be generated that are not previously known binary or ternary inorganic molecules. A second example of such chemistry and calculations is for the $\mathrm{M}_{\mathrm{x}} \mathrm{C}_{\mathrm{y}} \mathrm{H}_{\mathrm{z}}$ series for $\mathrm{M}=\mathrm{Be}, \mathrm{Mg}, \mathrm{Al}{ }^{36}$ (See Figure 3). These neutral molecules have been identified and characterized experimentally and suggested theoretically, based upon their positive identification through these established methods. The appropriate DFT calculations determine ionization energies and generate the experimental stiochiometries.

\section{B. Reactions with Covalent Clusters}

As mentioned above, chemical reactions with main group and some metal containing clusters have been explored in general in early studies. The more recent studies of the last 20 years are fashioned and modeled after condensed phase reactions in order to elucidate their catalytic behavior and mechanisms through cluster studies. Clusters containing metals, metal oxides, sulfides, and nitrides, mixed metal systems, catalyst supports, and photon driven systems are all of interest. The advantage of studying catalysis employing gas phase neutral clusters is that reactants and products are known, neutrals are probably more like the condensed phase catalytic species than are ions, and theory at various levels is more readily applicable to finite clusters than it is to surface defect sites or structural anomalies. ${ }^{37}$ Thus, the major application for current neutral covalent cluster studies is the generation of reaction mechanisms for catalytic species and reactions: cluster results, both experimental and theoretical, are employed to generate a catalytic cycle that can be used to understand and perhaps eventually to enhance the catalytic activity of a condensed phase catalyst. For example, if one learns from neutral cluster reactions 
that oxygen rich clusters are more reactive in the gas phase than oxygen poor clusters, then oxygen rich catalysts can be used for the condensed phase reaction. If this enhances the generation of product, the gas phase mechanism has been shown to be a useful model of the condensed phase process. Additionally, if the $\mathrm{VO}_{3}\left(\mathrm{~V}_{2} \mathrm{O}_{5}\right)_{\mathrm{n}}, \mathrm{n}=0,1,2,3, \ldots$, cluster series is reactive in the gas phase, such surface structures can be emphasized for condensed phase reaction studies and if this enhances product formation, again neutral cluster gas phase chemistry is a good model for condensed phase behavior. In all these reactivity studies, the end product for the research is a detailed, atomic, quantum mechanical potential energy surface mechanism for the chemistry, and a catalytic reaction cycle designed around a proposed, local surface reactive site, based on the reactive gas phase cluster structure. In some instances, a consistent reactivity structure emerges that can give general insight into the nature of the catalytic chemistry. Below we present specific examples of such neutral cluster studies, for which one can be certain that reactants and products are well documented both theoretically and experimentally, and for which both active and inactive clusters are explicated, in order to prove the theory and mechanism.

Nonetheless, the exploration of covalent neutral clusters as catalytic species is not as advanced as the study of vdW clusters, discussed earlier, to elucidate intermolecular interactions and excited state chemistry. This is partly because of the development of SP1 and high energy/photon lasers as experimental techniques, and a vastly improved theoretical approach to cluster studies through quantum chemistry techniques such as DFT, CASSCF, multi reference and perturbation algorithms, and $\operatorname{CCSD}(\mathrm{T})$. We can also add that van de Waals clusters and crystals are more amenable to well-known approximate methods, based on accurate molecular quantum chemistry, than are covalent species that can be unknown in terms of structure and energy levels. 
Some themes that are now emerging for catalytic behavior of covalent clusters can be suggested: oxygen centered radicals; supports for specific reactive centers, such as $\mathrm{VO}_{3}, \mathrm{O}$; mixed metal support systems of active sites; and photo generated reactions in which conical interactions between excited and ground state potential energy surfaces play a central role, as new regions of the neutral cluster ground state structures can be accessed and explored, and all of the photon energy can be transferred from electronic to vibrational degrees of freedom to be employed in the chemical reactivity. Thus, while we will present the data for these themes below, we are not yet at the stage in neutral covalent catalytic reaction cluster studies for which real conclusions can be drawn for fundamental generalization. We suggest caution here in order to be secure in the ideas and reaction mechanisms that begin to emerge and the general behavior that we assign for condensed phase catalytic systems. Most condensed phase catalytic behavior is at present assigned to either bulk or surface defects, for which fundamental generalizations for atomic level mechanisms are not typically feasible.

Roughly 20 studies have appeared concerning neutral gas phase cluster modeling of condensed phase catalytic processes. We will briefly review these below because they not only demonstrate detailed mechanisms for these catalytic processes, but they also begin to express general themes and directions for these and future studies.

The first report of a neutral cluster catalytic study was for the reaction of $\mathrm{SO}_{2}+\mathrm{O}_{2} \rightarrow$ $\mathrm{SO}_{3}$ supported on $\mathrm{V}_{\mathrm{x}} \mathrm{O}_{\mathrm{y}}$ clusters. This condensed phase reaction has a long history of confusing and conflicting proposals for mechanisms: ${ }^{35 a, 38}$ no wonder, two mechanisms are found for gas phase neutral clusters. For oxygen rich clusters like $\mathrm{V}_{2} \mathrm{O}_{6,7}, \mathrm{SO}_{3}$ is made directly. For oxygen, poor clusters, like $\mathrm{V}_{2} \mathrm{O}_{2,3}$, the product is $\mathrm{SO}$ : $\mathrm{SO}$ then reacts directly with $\mathrm{O}_{2}$ present in the input flow and $\mathrm{SO}_{3}$ is generated. Thus two pathways exist for $\mathrm{SO}_{2}+\mathrm{O}_{2} \rightarrow \mathrm{SO}_{3}$ catalyzed by a 
vanadium oxide catalyst. The regeneration path for the catalyst can be directly through reaction with $\mathrm{O}_{2}$ or through two reaction sites disproportionating, for $\mathrm{V}_{\mathrm{x}} \mathrm{O}_{\mathrm{y}-1}+\mathrm{V}_{\mathrm{x}} \mathrm{O}_{\mathrm{y}+1} \rightarrow 2 \mathrm{~V}_{\mathrm{x}} \mathrm{O}_{\mathrm{y}}$. (See Figure 4.)

$\mathrm{V}_{\mathrm{x}} \mathrm{O}_{\mathrm{y}}$ clusters of the form $\left(\mathrm{V}_{2} \mathrm{O}_{5}\right)_{\mathrm{n}}\left(\mathrm{VO}_{3}\right), \mathrm{n}=0,1,2,3$, have been shown to activate $\mathrm{C}=\mathrm{C}$ bonds to generate $\mathrm{H}_{2} \mathrm{CO},{ }^{39}$ in a proposed, sustaining catalytic cycle in the presence of added $\mathrm{O}_{2}$ to replenish the original $\mathrm{V}_{x} \mathrm{O}_{y}$ stoichemistry. This cyclic reactivity theme is indicative of $\mathrm{V}_{x} \mathrm{O}_{y}$ structures as catalytic species: ${ }^{40}$ similar behavior is observed for $\mathrm{C}_{2} \mathrm{H}_{4}, \mathrm{C}_{3} \mathrm{H}_{6}, \mathrm{C}_{4} \mathrm{H}_{8}$, and $\mathrm{C}_{4} \mathrm{H}_{6}$. Clusters $\left(\mathrm{V}_{2} \mathrm{O}_{5}\right) \mathrm{VO}_{2}\left(\mathrm{CH}_{2}\right),\left(\mathrm{C}_{2} \mathrm{H}_{4}\right),\left(\mathrm{C}_{3} \mathrm{H}_{4}\right)$, and $\left(\mathrm{C}_{3} \mathrm{H}_{6}\right)$ are observed. These results indicate that $\mathrm{C}=\mathrm{C}$ bonds can be broken on $\mathrm{VO}_{3}\left(\mathrm{~V}_{2} \mathrm{O}_{5}\right)_{\mathrm{n}}, \mathrm{n}=0,1,2,3, \ldots$ clusters. Thereby, $\mathrm{C}=\mathrm{C}$ double bonds can be activated by oxygen rich clusters: $\mathrm{H}_{2} \mathrm{CO}$ and $\mathrm{H}_{2} \mathrm{O}$ are the released products for these systems. A catalytic, cyclic mechanism is supported by both theory and experiment. (See Figure 5.) Reactions of these catalytic clusters with $\mathrm{C}_{6} \mathrm{H}_{6}$ yields $\left(\mathrm{V}_{2} \mathrm{O}_{5}\right)_{n} \mathrm{VO}_{2} \mathrm{C}_{6} \mathrm{H}_{4}: \mathrm{C}_{2} \mathrm{~F}_{4}$ does not react with these $\mathrm{V}_{\mathrm{x}} \mathrm{O}_{\mathrm{y}}$ clusters. Again theory and experiment can merge with the generation of an allowed thermodynamic and kinetic mechanism for these reactions. $\mathrm{VO}_{3}(\mathrm{n}=0$ for the above systems) reactions with propylene are also calculated. Again, $\mathrm{CH}_{3} \mathrm{CHO}+\mathrm{VO}_{2} \mathrm{CH}_{2}$ and $\mathrm{HCHO}+$ $\mathrm{VO}_{2}\left(\mathrm{CHCH}_{3}\right)$ reactions are thermodynamically and kinetically allowed. Small kinetic barriers are calculated for hydrogen transfer products $\mathrm{H}_{2} \mathrm{O}+\mathrm{VO}_{2} \mathrm{C}_{3} \mathrm{H}_{4}, \mathrm{CH}_{2} \mathrm{CHCHO}+\mathrm{VO}_{2} \mathrm{H}_{2}$, $\mathrm{CH}_{3} \mathrm{CH}_{2} \mathrm{CHO}+\mathrm{VO}_{2}$, and $\left(\mathrm{CH}_{3}\right)_{2} \mathrm{CO}+\mathrm{VO}_{2}$. Regeneration of $\mathrm{VO}_{3}$ clusters with $\mathrm{O}_{2}$ is cyclically available without kinetic or thermodynamic barriers. These neutral cluster results parallel similar observations in the condensed phase for the $\mathrm{V}_{2} \mathrm{O}_{5} / \mathrm{SiO}_{2}$ catalyst. These results for $\mathrm{VO}_{3}\left(\mathrm{~V}_{2} \mathrm{O}_{5}\right)_{\mathrm{n}}$ strongly suggest an active role for catalytic support systems, and for support systems in general, as will be suggested below. 
$\mathrm{V}_{\mathrm{x}} \mathrm{O}_{\mathrm{y}}$ clusters can also catalytically react with $\mathrm{CH}_{3} \mathrm{OH}$ and $\mathrm{CD}_{3} \mathrm{OH}{ }^{40 \mathrm{c}}$ Association products are observed for most clusters. For oxygen deficient clusters, a hydrogen atom is obstructed from the methyl group of methanol. For oxygen rich clusters, hydrogen can be abstracted from both methanol methyl and $\mathrm{OH}$ moieties. Dehydration products can also be formed such as $\left(\mathrm{VO}_{2}\right)_{\mathrm{n}}\left(\mathrm{VO}_{3}\right)_{\mathrm{n}}\left(\mathrm{CH}_{3}\right)_{2} \mathrm{n}, \mathrm{m}=0,1,2,3, \ldots$ Calculations support these observed reactions.

$\mathrm{V}_{\mathrm{x}} \mathrm{O}_{\mathrm{y}}$ clusters can also be catalytic for the reduction of $\mathrm{NO}$ with $\mathrm{NH}_{3}$ to generate $\mathrm{N}_{2}$ and $\mathrm{H}_{2} \mathrm{O}$, assisted particularly by clusters $\mathrm{VO}_{3}$ and $\mathrm{V}_{2} \mathrm{O}_{5} \cdot{ }^{40 \mathrm{~d}}$ in general, oxygen rich clusters are most active. On the other hand, $\mathrm{Ta}_{\mathrm{m}} \mathrm{O}_{\mathrm{n}}$ species form mixed clusters, $\mathrm{Ta}_{\mathrm{m}} \mathrm{O}_{\mathrm{n}}(\mathrm{NO})_{\mathrm{x}}\left(\mathrm{NH}_{3}\right)_{\mathrm{y}}$, that remain stable. Again, a catalytic cycle can be generated for the reactive $\mathrm{V}_{\mathrm{x}} \mathrm{O}_{\mathrm{y}}$ clusters.

A final note on the versatility of the neutral vanadium oxide system is for the reaction $\mathrm{CO}$ $+\mathrm{N}_{2} \mathrm{O} \rightarrow \mathrm{CO}_{2}+\mathrm{N}_{2}{ }^{41}$ The observed reactions are $\mathrm{VO}_{2}+\mathrm{N}_{2} \mathrm{O} \rightarrow \mathrm{VO}_{3}+\mathrm{N}_{2}, \mathrm{VO}_{3}+\mathrm{CO} \rightarrow \mathrm{VO}_{2}$ $+\mathrm{CO}_{2}$ : the couple $\mathrm{VO}_{2} / \mathrm{VO}_{3}$ is complete at room temperature for the oxidation/reduction reaction. Calculations show that the entire catalytic process is overall barrierless and thermodynamically allowed.

A very interesting and unexpected cyclic reaction with metal clusters occurs for neutral $\mathrm{Nb}_{\mathrm{n}}$. In this instance the particularly active cluster is $\mathrm{Nb}_{8}$ which supports the reaction $\mathrm{CO}+2 \mathrm{H}_{2}$ $\rightarrow \mathrm{CH}_{4} \mathrm{O}$ at ca. $350 \mathrm{~K}$ in a flow cell. ${ }^{42}$ The reverse reaction for $\mathrm{Nb}_{\mathrm{n}}$ with $\mathrm{CH}_{3} \mathrm{OH}$ yield only clusters $\mathrm{Nb}_{8,10}\left(\mathrm{CH}_{3} \mathrm{OH}\right)$ surviving, while other $\mathrm{Nb}_{\mathrm{n}}$ clusters do not generate addition complexes with $\mathrm{CH}_{3} \mathrm{OH}$. A catalytic cycle for $\mathrm{Nb}_{8}$ with $\mathrm{CO} / \mathrm{H}_{2}$ is developed and neutral $\mathrm{Nb}_{8}$ is the particular structure that is catalytically active. (See Figure 6.)

Vanadium sulfide is additionally known as a versatile and important catalyst for condensed phase systems: neutral clusters $\mathrm{V}_{\mathrm{m}} \mathrm{S}_{\mathrm{n}}$ can also be responsible for a considerable 
variety of chemistry. ${ }^{43}$ For example, ethylene can be hydrogenated on $\mathrm{V}_{\mathrm{m}} \mathrm{S}_{\mathrm{n}}$ clusters to generate $\mathrm{V}_{\mathrm{m}} \mathrm{S}_{\mathrm{n}} \mathrm{C}_{2} \mathrm{H}_{\mathrm{x}}$ with $(\mathrm{m}=1, \mathrm{n}=1-3, \mathrm{x}=4-6$; and $\mathrm{m}=2, \mathrm{n}=1-5, \mathrm{x}=4-6)$. Calculations support these observations and a kinetically and thermodynamically allowed reaction set and catalytic cycle can be prepared. $\mathrm{S}$ atoms bonding with $\mathrm{V}$ atoms play an active role in the mechanism and cycle. This system is very reactive and given the right $\mathrm{V}_{2} \mathrm{~S}_{2}$ surface exposure, this should be a very effective reactive process. (See Figure 7.)

Iron sulfide is also an effective catalyst for the synthesis of methanol and formaldehyde from carbon monoxide and hydrogen. ${ }^{44}$ Products are identified with the reaction $\mathrm{FeS}+\mathrm{CO} \rightarrow$ $\mathrm{Fe}+\mathrm{OCS}$ and $\mathrm{Fe}_{2} \mathrm{~S}_{2} \mathrm{CO}$ if only $\mathrm{CO}$ is present for the reaction. With $\mathrm{CO}+\mathrm{H}_{2}$ the cluster $\mathrm{Fe}_{2} \mathrm{~S}_{2} \mathrm{COH}_{4}$ is detected. Calculations yield the overall process $\left(\mathrm{Fe}_{2} \mathrm{~S}_{2}+\mathrm{CH}_{3} \mathrm{OH}+\mathrm{CH}_{2} \mathrm{O}\right)$ barrierless and thermodynamically allowed, for both stoichiometries. The catalytic cycle proposed gives a condensed phase mechanism for the overall reaction. (See Figure 8.)

An interesting observation for neutral heavy metal cluster catalysis can be mentioned for gold clusters. ${ }^{45}$ The reactions of $\mathrm{Au}_{3}(\mathrm{CO})_{2,3}, \mathrm{Au}_{5}(\mathrm{CO})_{4}$, and $\mathrm{Au}_{7}(\mathrm{CO})_{4,5}$ with $\mathrm{O}_{2}$ is characterized through SPI TOFMS. These reactant features decrease significantly in the presence of $\mathrm{O}_{2}$ in a fast flow reactor. Non-relativistic calculations show a significant barrier for the generation of $\mathrm{Au}_{3}$ and $\mathrm{CO}_{2}$, but relativistic DFT calculations predict an allowed, barrierless reaction for $\mathrm{O}_{2}$ but not $\mathrm{N}_{2} \mathrm{O}$, as is observed.

Neutral clusters of $\mathrm{Co}_{\mathrm{m}} \mathrm{N}(\mathrm{m}=6-10)$ can be converted to $\mathrm{Co}_{6,10}\left(\mathrm{NH}_{2}\right)$ and $\mathrm{Co}_{7,8,9}\left(\mathrm{NH}_{3}\right)$ through reaction with $\mathrm{H}_{2}$ at $300-400 \mathrm{~K}$. These observations imply that $\mathrm{Co}_{\mathrm{m}} \mathrm{N}$ clusters have a high reactivity with $\mathrm{H}_{2}$ to generate ammonia. ${ }^{46}$ The odd number of $\mathrm{H}$ atoms for $\mathrm{Co}_{\mathrm{m}} \mathrm{NH}_{3}$ suggests that hydrogen molecule dissociation occurs on two active cobalt nitride clusters and this is the key step in the formation of $\mathrm{NH}_{3}$ in the gas phase reaction. A catalytic cycle for ammonia generation 
from $\mathrm{N}_{2}$ on the cobalt metal catalyst surface is proposed based on cluster experimental and theoretical results. (See Figure 9.)

As a final example of traditional catalytic studies employing gas phase, neutral metal containing, covalent clusters, the reactivity and catalytic cycle for manganese oxide clusters is presented. ${ }^{47}$ Reactions are explored for $\mathrm{Mn}_{\mathrm{m}} \mathrm{O}_{\mathrm{n}}$ with $\mathrm{CO}, \mathrm{NO}_{2}, \mathrm{O}_{2}, \mathrm{C}_{2} \mathrm{H}_{4}$ and a strong size dependent behavior is characterized. For example, $\mathrm{Mn}_{2} \mathrm{O}_{5} / \mathrm{Mn}_{3} \mathrm{O}_{7}+\mathrm{CO} \rightarrow \mathrm{Mn}_{2} \mathrm{O}_{4} / \mathrm{Mn}_{3} \mathrm{O}_{6}+$ $\mathrm{CO}_{2}$ and $\mathrm{Mn}_{2} \mathrm{O}_{\mathrm{n}}$ clusters are readily re-oxidized by $\mathrm{NO}_{2}$, while only association products are found for the reactions $\mathrm{Mn}_{2} \mathrm{O}_{3-5} / \mathrm{Mn}_{3} \mathrm{O}_{5-7}+\mathrm{C}_{2} \mathrm{H}_{4}$. This activation suggests that a catalytic cycle can be established for the cluster $\mathrm{Mn}_{2} \mathrm{O}_{5}: \mathrm{Mn}_{2} \mathrm{O}_{5}+\mathrm{CO}+\mathrm{NO}_{2} \rightarrow \mathrm{Mn}_{2} \mathrm{O}_{4}+\mathrm{CO}_{2}+\mathrm{NO}_{2} \rightarrow$ $\mathrm{Mn}_{2} \mathrm{O}_{5}+\mathrm{CO}_{2}+\mathrm{NO}$. Calculations support these reactions, but the reaction $\mathrm{Mn}_{2} \mathrm{O}_{5}+\mathrm{C}_{2} \mathrm{H}_{4} \rightarrow$ $\mathrm{Mn}_{2} \mathrm{O}_{4}+\mathrm{CH}_{3} \mathrm{CHO}$, does not go to products due to a significant barrier on the reaction potential energy surface.

In the last few paragraphs we have presented and discussed what might be called traditional or direct models for employing neutral cluster, gas phase chemistry to find detailed quantum mechanical, atomic level reaction mechanisms for condensed phase catalytic cycles. The motivation for this program can be stated as follows: if we know the reaction mechanism for a given process, we can tune reactants and conditions to improve its yield and stability. The above examples support this thesis.

We now turn attention to a few examples of cluster reactions that explore new reactions and new concepts for catalytic systems. The suggestion for these studies come from work on "supported active sites," such as $\left(\mathrm{V}_{2} \mathrm{O}_{5}\right)_{\mathrm{n}}\left(\mathrm{VO}_{3}\right)$ clusters, the importance of electronic potential energy surfaces and their interactions for chemical reactions, and the nature and function of support systems for condensed phase catalysis, in general. This will demonstrate that neutral 
cluster studies can break new ground for the fundamental understanding of condensed phase catalysis. These examples include: 1 . neutral binary metal oxide clusters; 2 . C-H bond activation through different cluster spin states; 3. photocatalysis and conical intersections for different electronic potential energy surfaces; and 4. the catalytic behavior of support and mixed support systems.

$\mathrm{VCoO}_{4}$ is the active cluster for the reaction $\mathrm{VCoO}_{4}+\mathrm{CO} \rightarrow \mathrm{VCoO}_{3}+\mathrm{CO}_{2}{ }^{48}$ The first step in the mechanism involves a OC-V attachment for a cluster structure with two bridging $\mathrm{O}$ atoms bonding $\mathrm{V}$ and $\mathrm{Co}$ and two terminal $\mathrm{O}$ atoms on $\mathrm{Co}$. In this case both metal atoms contribute to the oxidation mechanism and the full reaction cycle.

$\mathrm{V}_{2} \mathrm{O}_{5}$ is shown to react with butane ${ }^{49}$ for dehydrogenation to generate $\mathrm{V}_{2} \mathrm{O}_{5} \mathrm{H}_{2}$ and $\mathrm{C}_{4} \mathrm{H}_{8}$. The reaction appears to saturate for high concentrations of $\mathrm{C}_{4} \mathrm{H}_{10}$ in the reaction cell, suggesting that the $\mathrm{V}_{2} \mathrm{O}_{5}$ cluster may be present in two different electronic states. Calculations show that the ground state singlet $\mathrm{V}_{2} \mathrm{O}_{5}$ is unreactive, while the lowest energy excited triplet state $\mathrm{V}_{2} \mathrm{O}_{5}$ (at + $0.7 \mathrm{eV}$ ) is reactive. Regeneration of the catalyst $\mathrm{V}_{2} \mathrm{O}_{5}\left(\mathrm{H}_{2}\right)$ can be accomplished with $\mathrm{O}_{3}$ or for two $\mathrm{V}_{2} \mathrm{O}_{5}\left(\mathrm{H}_{2}\right)$ species with $\mathrm{O}_{2}$. Whether this is eventually a practical catalytic process is not actually the point: this chemistry and mechanism are a demonstration of what subtle possibilities catalytic processes can entail.

Photo-induced reactions are becoming more prominent in the catalysis area, especially considering the oxidation of $\mathrm{H}_{2} \mathrm{O}$ to $\mathrm{H}_{2}$ and $\mathrm{O}_{2}$ on a titanium oxide catalyst in the presence of visible light. ${ }^{50}$ Cluster studies yield $\mathrm{Ti}_{2} \mathrm{O}_{4}\left(\mathrm{H}_{2} \mathrm{O}\right)$ and $\mathrm{Ti}_{2} \mathrm{O}_{5}\left(\mathrm{H}_{2} \mathrm{O}\right)$ clusters for the neutral system. Irradiation with visible laser light $(532 \mathrm{~nm})$ yields the $\mathrm{Ti}_{2} \mathrm{O}_{4}\left(\mathrm{H}_{2} \mathrm{O}\right)$ cluster unchanged but the $\mathrm{Ti}_{2} \mathrm{O}_{5}\left(\mathrm{H}_{2} \mathrm{O}\right)$ cluster vanishes while the $\mathrm{Ti}_{2} \mathrm{O}_{4}$ cluster intensity increases slightly. Calculations are consistent with these results, but both the ground state and the excited state have high enough 
barriers to $\mathrm{H}_{2} \mathrm{O}_{2}$ or $\mathrm{H}_{2}+\mathrm{O}_{2}$ formation that the reaction is not allowed. More advanced theory shows that $\mathrm{S}_{1} / \mathrm{S}_{0}$ conical intersection occurs between these two states and provides enough energy for the $\mathrm{Ti}_{2} \mathrm{O}_{5}\left(\mathrm{H}_{2} \mathrm{O}\right)+\mathrm{h} v \rightarrow \mathrm{Ti}_{2} \mathrm{O}_{4}+\mathrm{H}_{2} \mathrm{O}_{2}$ reaction to occur. The $\mathrm{Ti}_{2} \mathrm{O}_{4} \mathrm{H}_{2} \mathrm{O}$ cluster does not absorb in the visible and cannot undergo the reaction. This is a new atomic mechanistic path for such reactions. (See Figure 10.)

As mentioned, support systems (e.g., $\mathrm{CeO}_{2}, \mathrm{Al}_{2} \mathrm{O}_{3}, \mathrm{SiO}_{2}, \mathrm{TiO}_{2}, \ldots$ ) are an essential component of actual catalysts employed in industrial settings. Study of the role of a support substance can also be pursued through modeling with gas phase, neutral clusters. To this end, $\mathrm{Ce}_{\mathrm{x}} \mathrm{Al}_{\mathrm{y}} \mathrm{O}_{\mathrm{z}}$ clusters can be generated and their reactivity properties can be explored: initial reactions with $\mathrm{CO}$ and $\mathrm{C}_{4} \mathrm{H}_{10}$ are reported and explained for this mixed support cluster series. ${ }^{51}$ The very reactive cluster $\mathrm{CeAlO}_{4}$ undergoes oxygen atom transfer with $\mathrm{CO}$ and hydrogen atom transfer with butane. The structure of this cluster has two bridging oxygen atoms and a terminal $\mathrm{O}$ atom on each metal site: an unpaired electron is located on the terminal $\mathrm{O}$ atom on the $\mathrm{Al}$ site. The $\mathrm{O}$ centered radical plays a dominant role in the cluster chemistry with regard to both hydrogen and oxygen atoms transfers. The essential feature for this reactivity and catalytic cycle is the presence of the $\mathrm{O} \bullet$ terminal radical site in the cluster, as both atom transfers focus on this site. Apparently the metal atoms support the active site $\mathrm{O} \bullet$ but are not it. Such results are found for both ionic (cation and anion) as well as neutral clusters. Reference 51 has a rather detailed and complete set of references to the importance of oxygen centered radicals for both charged and neutral covalent clusters.

\section{PROSPECTIVES - WHAT NEXT FOR MASS SPECTROMETRY AND NEUTRAL CLUSTERS?}


A famous quote has been reported and recorded many times: "It is difficult to make predictions, especially about the future." (M. Aurelius, Confucius, Old Chinese Proverb, Y. Berra, N. Bohr, A. Einstein, F. Dyson, W. Rogers, M. Twain, G. B. Shaw, G. Marx, E. Fermi,...). Nonetheless, we launch onto this lumpy path, being mindful of the situation one might face pre-1984 for the study of small carbon clusters. In 1983 one would predict that $C_{n}$ clusters, $\mathrm{n}=1, \ldots, 10$, serve as an astrochemistry model for very low concentration species. Funding for such studies might be difficult to secure.

Mass spectrometry is a venerable and useful tool for the characterization of gas phase species: studying clusters as special entities is difficult to imagine without it. The major advantages of the study of neutral clusters is that their properties can be readily calculated and that their stoichiometry is known, even to the presence of an $\mathrm{H}$ atom otherwise missed. Given mass detection, one can access clusters such as $\left(\mathrm{H}_{2} \mathrm{O}\right)_{\mathrm{n}}(\text { rare gas })_{\mathrm{x}}$ and use this information to measure cluster absorption of energy from laser excitation of vibrational, electronic, and vibronic states, as some or all of the rare gas $(\mathrm{RG})$ atoms fragment from $\left(\mathrm{H}_{2} \mathrm{O}\right)_{\mathrm{n}}(\mathrm{RG})_{\mathrm{x}}+\mathrm{h} v \rightarrow\left(\mathrm{H}_{2} \mathrm{O}\right)_{\mathrm{n}}$ $(R G)_{x-y}+y R G$. In this manner an absorption spectrum of a vdW or covalent cluster can be mapped. Clearly laser development does, and will continue to, play a dominant role in the study of neutral clusters. Tunable laser radiation can now be generated from ca. $20 \mu \mathrm{m}$ to $100 \mathrm{~nm}$, employing ns, ps, fs time resolution: cluster energy levels, dynamics, and kinetics can be studied for a system that can be treated at an appropriately high level of theory.

With the advent of as lasers, new forms of cluster dynamics can be probed. The motion of electrons can be mapped with ca. 100 as pulses, which are now available, even through commercial lasers. A laser pulse with a time duration of 1 ps has a $\sim 5 \mathrm{~cm}^{-1}$ uncertainty limited energy width, and is still a potential spectroscopic tool. But a 100 fs or 10 fs or 1 fs duration 
pulse does not just improve time resolution for dynamics and kinetics; it also excites an entirely different set of energy levels for each time resolved pulse and now generates a coherent wave packet of modes (electronic or vibronic) that will display more information about the laser than about the cluster system. For as excitations, neutral and ion states are completely, coherently mixed. All of this leaves a lot of territory for exploration of clusters as small pieces of matter or as model species for condensed phase properties.

Using multiple laser pulses to study neutral clusters is of course a current reality: REMPI (one- and two-color, and multiple photons from each laser, e.g., 2+1, 2+2, etc.) can be employed to investigate cluster vibrational spectra and dynamics, and coherent behavior as well.

Tunable lasers from 7-16 eV energy/photon would be a major advance for the mass related study of neutral clusters, as threshold ionization would then be significantly easier: at present, either considerable non-linear optical efforts are required or synchrotron radiation at a national laboratory must be planned.

At present, neutral clusters with more than 50 molecules or atoms for either vdW or covalent clusters are considered quite large, with regard to energy level determination and calculations. Synthesis of such large clusters is difficult but would be very helpful for the development of new spectroscopic and theoretical techniques, as such clusters interface smoothly with the nano world. Laser ablation does not appear to be a best method for generation of such large clusters, except in special cases. ${ }^{52}$

As pointed out at the beginning of this review, cluster samples in a supersonic expansion are inhomogeneous. This can be a disadvantage for the study of individual cluster properties and reactions, if cluster size specific information is required for the analysis of cluster behavior. At present this is not an actively addressed or solved problem. 
One solution to this problem is an involved one that should generate single cluster results but at the expense of cluster signal intensity: this approach may not yield sufficient cluster numbers to study reactions, for example. Begin the cluster generation process with negative ions. These species can be made more abundant by electron attachment with laser generated, low energy $(\leq 1 \mathrm{eV})$ electrons. These clusters can then be sorted in a TOFMS and, using a mass gate, one ionic cluster can be selected for photo-detachment at threshold (typically with a doubled $\mathrm{Nd}^{+3} /$ YAG laser output or a dye laser). One then has a mass selected neutral cluster for IR, visible, UV, photo-electron spectroscopies, as is of interest. This may not work for all clusters, but should work for some.

So, with all these tools at one's disposal, what clusters will be most interesting for future study?

With regard to van der Waals clusters the trend now that should continue for years to come is toward larger, more complicated solute molecules of a biological nature with hydrogen bonding solvents. Thus, , , $\gamma$ - substituted organic acids, specifically amino acids, peptides, and saccharides and polysaccharides with water and alcohols as solvents should prove particularly interesting subjects for investigation. Additionally, various drug and neurotransmitter molecules can also be of interest in this grouping. These clusters can be studied for structural and spectroscopic information and, as well, for time resolved behavior.

The behavior of these clusters upon ionization can give information concerning the fragmentation behavior of biological molecules, with and without solvation. Radiation damage of biopolymers such as proteins, DNA, RNA, carbohydrates, etc. is an important issue for many disease related problems. Both ground, and excited valence and Rydberg electronic state proton, hydrogen atom, and electron transfers can occur in solute/solvent van der Waals clusters; these 
reactions can be kinetic or coherent wave packet driven. Determining the nature of these excited vibrational or electronic state reactions would be a valuable addition to our understanding of biological molecular phenomena.

Covalent clusters with mixed and pure metals also are amenable to both time resolved and energy resolved single-and multi-photon excitations. Excited electronic state energies and their relaxation and non-adiabatic coupling interactions are important if one wishes to understand photo-catalytic reactions and cycles. One can also determine the extent to which coherent transfer of energy plays a role in the reaction chemistry.

Of course new systems are always a possibility for covalent clusters: $\mathrm{C}_{60,70,84, \ldots,} \mathrm{Al}_{\mathrm{x}} \mathrm{C}_{\mathrm{y}} \mathrm{H}_{\mathrm{z}}$, $\mathrm{Be}_{\mathrm{x}}, \mathrm{C}_{\mathrm{y}} \mathrm{H}_{\mathrm{z}}, \mathrm{Mg}_{\mathrm{x}} \mathrm{C}_{\mathrm{y}} \mathrm{H}_{\mathrm{z}}$, are just a few examples. One must always be alert to such serendipitous findings.

\section{ACKNOWLEDGMENTS}

These studies have been supported over the years by the US NSF, ARO, AFOSR, ONR, and DOE. My students and post doctoral fellows have been well referenced in this review, but they deserve special appreciation for their efforts, talents, and dedication: none of this work would have been possible without them. I especially thank Dr. Shi Yin for his help with the included figures in the manuscript. 


\section{REFERENCES}

1. Atomic and Molecular Clusters, Ed. E. R. Bernstein, (Studies in physical and theoretical chemistry 68), (Elsevier, Amsterdam, 1990).

2. a. J. B. Anderson, R. P. Andres and J. B. Fenn, Adv. Chem. Phys., 10, 275 (1966). b. A. Kantrowitz and J. Grey, Rev. Sci. Inst. 22, 328 (1951). c. D. H. Levy, Adv. Chem. Phys. 47 (pt. 1), 323 (1981), and references therein. d. M. A. Duncan, T. G. Dietz and R. E. Smalley, Chem. Phys. 44 (415) (1979). e. T. G. Dietz, M. A. Duncan and R. E. Smalley, J. Chem. Phys. 746511 (1979). f. Y. Xie, E. R. Bernstein, "Laser Ionization Cluster Sources and Their Applications", Encyclopedia of Mass Spectrometry 5, 557 (2010), D. Beauchemin, D. E. Mathews, ed. (Elsevier, Amsterdam)

3. K. Law, M. Schauer and E. R. Bernstein, J. Chem. Phys. 81, 4871 (1984.

4. M. Schauer, K. Law and E. R. Bernstein, J. Chem. Phys. 82, 726 (1985).

5. a.J. Wanna and E. R. Bernstein, J. Chem. Phys. 84, 927 (1986). b. J. A. Menapace and E. R. Bernstein, J. Phys. Chem. 91, 2533 (1987). c. A. J. Gotch, A. W. Garrett, D. L. Severance and T. S. Zwier, Chem. Phys. Lett. 178, 121 (1991). d. A. J. Gotch and T. S. Zwier, J. Chem. Phys. 96, 3388 (1992). e. J. D. Augspurger, C. E. Dykstra and T. S. Zwier, J. Phys. Chem. 96, 7252 (1992). f. R. N. Pribble and T. S. Zwier, Faraday Discuss. 229 (1994). g. R. N. Pribble, A. W. Garrett, K. Haber and T. S. Zwier, J. Chem. Phys. 103, 531 (1995). h. C. J. Gruenloh, J. R. Carney and C. Arrington, Science 276, 1678 (1997). i. A. W. Garrett and T. S. Zwier, J. Chem. Phys. 96, 3402 (1992). j. A. W. Garrett, D. L. Severance and T. S. Zwier, J. Chem. Phys. 96, 7245 (1992). k. J. D. Augspurger, C. E. Dykstra and T. S. Zwier, J. Phys. Chem. 97980 (1993). 1. A. J. Gotch, R. N. Pribble, F. A. Ensminger and T. S. Zwier, Laser Chem. 13187 (1994). m. K. Kim, K. D. Jordan and T. S. Zwier, J. Am. Chem. Soc. 11611568 (1994). n. R. N. Pribble and T. S. Zwier, Science 265, 75 (1994).

6. M. Ito, T. Ebata and M. Mikami, Ann. Rev. Phys. Chem. 39, 123 (1988).

7. J. A. Menapace and E. R. Bernstein, J. Chem. Phys. 87, 6877 (1987)

8. a. D. Nachtigallováa, H. Lischka, J. Szymczak, M. Barbatti, P. Hobza, Z. Gengeliczki, G. Pino, P. Callahan and M. S. de Vries, Phys. Chem. Chem. Phys. 12, 4924 (2010). b. B. O. Crews, A. Abo-Riziq, K. Pluhacková, P. Thompson, G. Hill, P. Hobza and M. S. de Vries, Phys. Chem. Chem. Phys. 12, 3597 (2010). c. Z. Gengeliczki, M. P. Callahan, N. Svadlenak, C. I. Pongor, B. Sztáray, L. Meerts, D. Nachtigallováa, P. Hobza, M. Barbatti, H. Lischka and M. S. de Vries, Phys. Chem. Chem. Phys. 12, 5375 (2010). d. M. P. Callahan, A. Abo-Riziq, B. Crews, L. Grace and M. S. de Vries, Spectrochimica Acta Part A71, 1492 (2008). e. A. M. Rijs, M. S. de Vries, J. S. Hannam, D. A. Leigh, M. Fanti, F. Zerbetto and W. J. Buma, Angewandte Chemie Int. Ed. 47, 3174 (2008). f. M. S. de Vries and P. Hobza, Ann. Rev. of Phys. Chem. 58, 585 (2007). g. A. Abo-Riziq, B. O. Crews, M. P. Callahan, L. Grace and M. S. de Vries, Angewandte Chemie, 118, 5290 (2006). h. A. Abu-Riziq, L. Grace, P, Hobza and M. S. de Vries, Proceedings of the National Academy of Sciences of the United States of America, 102, 20 (2005). i. E. Nir, C. Plutzer, K. Kleinermanns and M. S. de Vries, European Physical Journal D, 20317 (2002). j. M. S. de Vries, Nature 408, 949 (2000).

9. J. W. Shin and E. R. Bernstein, J. Chem. Phys. 140, 044330 (2014).

10. a. Y. Hu, J. Guan and E. R. Bernstein, Mass Spectrom. Rev. 32,484 (2013). b. A. Bhattacharya and E. R. Bernstein, J. Phys. Chem. A 115, 10679 (2011). c. J.-W. Shin, F. Dong, M. E. Grisham, J. J. Rocca and E. R. Bernstein, Chem. Phys. Lett. 506, 161 (2011). d. A. Bhattacharya, J.-W. Shin, K. J. Clawson and E. R. Bernstein, Phys. Chem. Chem. Phys. 12, 9700 (2010). e. J.-W. 
Shin and E. R. Bernstein, (Invited Review) Trends Appl. Spectrosc. 7, 47 (2009). f. Y. J. Hu and E. R. Bernstein, J. Phys. Chem. A 113, 8454 (2009). g. Y. J. Hu and E. R. Bernstein, J. Chem. Phys. 128, 164311 (2008). h. Y. J. Hu, H. B. Fu and E. R. Bernstein, J. Chem. Phys. 124, 114305 (2006). i. Y. J. Hu, H. B. Fu and E. R. Bernstein, J. Phys. Chem. A 110, 2629 (2006). j. Y. J. Hu, H. B. Fu and E. R. Bernstein, J. Chem. Phys. 125, 184306 (2006). k. Y. J. Hu, H. B. Fu and E. R. Bernstein, J. Chem. Phys. 125, 184309 (2006).

11. a. H. Kang, C. Dedonder-Lardeux, C. Jouvet, S. Martrenchard, G. Grégoire, C. Desfrançois, J. P. Scherman,, M. Barat and J. A. Fayeton, Phys. Chem. Chem. Phys. 6, 2628 (2004). b. H. Kang, C. Jouvet, C. Dedonder-Lardeux, S. Martrenchard, G. Grégoire, C. Desfrançois, J. P. Schermann, M. Barat and J. A. Fayeton, Phys. Chem. Chem. Phys. 7, 394 (2005). c. G. Grégoire, C. Jouvet, C. Dedonder-Lardeux and A. L. Sobolewski, J. Am. Chem. Soc. 129, 6223 (2007). e. T. R. Rizzo, J. A. Stearns and O. V. Boyarkin, Int. Rev. Phys. Chem. 28, 481 (2009). f. C.-M. Tseng, M.-F. Lin, Y. L. Yang, Y. C. Ho, C.-K. Ni and J.-L. Chang, Phys. Chem. Chem. Phys. 12, 4989 (2011). g. M. Mališ, Y. Loquais, E. Gloaguen, H. S. Biswal, F. Piuzzi, B. Tardivel, V. Brenner, M. Broquier, C. Jouvet, M. Mons, N. Došlić and I. Ljubić, J. Am. Chem. Soc. 134, 20340 (2012). h. W. Chin, F. Piuzzi, I. Dimicoli and M. Mons, Phys. Chem. Chem. Phys. 8, 1033 (2006). i. W. Chin, I. Compagnon, J. P. Dognon, C. Canuel, F. Piuzzi, I. Dimicoli, G. von Helden, G. Meijer and M. Mons, J. Am. Chem. Soc. 127, 1388 (2005). j. W. Chin, J. P. Dognon, C. Canuel, F. Piuzzi, I. Dimicoli, M. Mons, I. Compagnon, G. von Helden and G. Meijer, J. Chem. Phys. 122 054317 (2005). k. W. Chin, J. P. Dognon, I. Dimicoli, B. Tardivel and M. Mons, J. Am. Chem. Soc. 127, 11900 (2005). 1. E. Gloaǵuen, B. de Courcy, J. P. Piquemal, J. Pilmé, O. Parisel, R. Pollet, H. S. Biswal, F. Piuzzi, B. Tardivel, M. Broquier and M. Mons, J. Am. Chem. Soc. 132, 11860 (2010). m. H. S. Biswal, Y. Loquais, B. Tardivel, E. Gloaǵuen and M. Mons, J. Am. Chem. Soc. 133, 3931 (2011). n. E. Gloaguen, Y. Loquais, J. A. Thomas, D. W. Pratt and M. Mons, J. Phys. Chem. B 117, 4945 (2013).

12. a. J. P. Simons, Mol. Phys. 107, 2435 (2009). b. E. G. Robertson, M. R. Hockridge, P. D. Jelfs and J. P. Simons, Phys. Chem. Chem. Phys. 3, 786 (2001). b. C. Cabezas, M. Varela and J. L. Alonso, Chem. Phys. Chem. 14, 2539 (2013). c. E. J. Cocinero, A. Lesarri, P. Ecija, F. J. Basterretxea, J.-U. Grabow, J. A. Fernandez and F. Castano, Angewandte Chemie-International Ed. 51, 3119 (2012). d. J. A. Fernandez and F. Castano, J. Am. Chem. Soc. 135, 2845 (2013). e. J. P. Simons, R. A. Jockusch, P. Carçabal, I. Hünig, R. T. Kroemer, N. A. Macleod and L. C. Snoek, Int. Rev. Phys. Chem. 24, 489 (2005). f. E. J. Cocinero, P. Carçabal, T. D. Vaden, J. P. Simons and B. G. Davis, Nature 469, 76 (2011).

13. a. J. Yao, H.-S. Im, M. Foltin and E. R. Bernstein, J. Phys. Chem. A 104, 6197 (2000) and references therein to older work. b. N. A. Macleod and J. P. Simons, Mol. Phys. 105, 689 (2007).

14. a. K. Muller-Dethlef and E. W. Schlag, Ann. Rev. Phys. Chem. 42, 109 (1991). b. A. Kammrath, J. R. R. Verlet, B. Griffin and D. M. Neumark, J. Chem. Phys. 125, 076101 (2006). c. A. Kammrath, J. R. R. Verlet, G. B. Griffin and D. M. Neumark, J. Phys. Chem. A 109, 7896 (2005).

15. a. S. Sun and E. R. Bernstein, J. Chem. Phys. 103, 4447 (1995). b. E. R. Bernstein, Ann. Rev. Phys. Chem. 46, 197 (1995). c. S. Sun and E. R. Bernstein, J. Phys. Chem. 100, 11348 (1996). d. R. Nowak, J. A. Menapace and E. R. Bernstein, J. Chem. Phys. 89, 1309 (1988). e. S. R. Lee, P. M. Felker, T. B. Pedersen, B. Fernandez and H. Koch, J. Chem. Phys. 118, 1230 (2003). f. P. M. Felker, J. Chem. Phys. 114, 7901 (2001).

16. P. R. Bunker and P. Jensen, Molecular Symmetry and Spectroscopy, $2^{\text {nd }}$ Ed. (NRC Press. Ottowa, 1998). 
17. a. H. S. Im, E R. Bernstein, J. Chem. Phys. 95, 6326 (1991). b. Q. Y. Shang, P. O. Moreno, R. Disselkamp and E. R. Bernstein, J. Chem. Phys. 98, 3703 (1993). c. D. P. Taylor, C. F. Dion and E. R. Bernstein, J. Chem. Phys. 106, 3512 (1997). d. G. J. Stueber, M. Foltin and E. R. Bernstein, J. Chem. Phys. 109, 9831 (1998). e. J. Fernandez, J. Yao and E. R. Bernstein, J. Chem. Phys. 110, 5183 (1999). f. J. Yao, J. Fernandez and E. R. Bernstein, J. Chem. Phys. 110, 574 (1999). g. M. Foltin, G. J. Stueber and E. R. Bernstein, J. Chem. Phys. 111, 9577 (1999). h. J. A. Bray and E. R. Bernstein, J. Phys. Chem. A 103, 2220 (1999).

18. a. S. Li and E. R. Bernstein, J. Chem. Phys. 97, 804 (1992) b. M. Hineman, D. F. Kelley and E. R. Bernstein, J. Chem. Phys. 99, 4533 (1993). c. R. Disselkamp and E. R. Bernstein, J. Chem. Phys. 98, 4339 (1993). d. M. Hineman, E. R. Bernstein, and D. F. Kelley, J. Chem. Phys. 98, 2516 (1993). e. M. Hineman, E. R. Bernstein and D. F. Kelley, J. Chem. Phys. 101, 850 (1994). f. Q. Y. Shang and E. R. Bernstein, Chem. Rev. 94, 2015 (1994). g. Q. Y. Shang, C. Dion and E. R. Bernstein, J. Chem. Phys. 101, 118 (1994). h. Q. Y. Shang and E. R. Bernstein, J. Chem. Phys. 100, 8625 (1994). i. Q. Y. Shang, P. O. Moreno and E. R. Bernstein, J. Am. Chem. Soc. 116, 311 (1994). j. D. P. Taylor and E. R. Bernstein, J. Chem. Phys. 103, 10453 (1995).

19. a. P. Hobza, H. L. Selzle and E. W. Schlag, Chem. Rev. 94, 1767 (1994) and references to older work therein. b. M. Schnell, U. Erlekam, P. R. Bunker, G. von Helden, J. U. Grabow, G. Meijer and A. van der Avoird, Phys. Chem. Chem. Phys. 15, 10207 (2013). c. A. K. Tummanapelli and S. Vasudevana, J. Chem. Phys. 139, 201102 (2013). d. A. van der Avoird, R. Podeszwa, K. Szalewicz, C. Leforestier, R. van Harrevelt, P. R. Bunker, M. Schnell, G. von Helden and G. Meijer, Phys. Chem. Chem. Phys. 12, 8219 (2010). e. T. Janowski and P. Pulay, Chem. Phys. Lett. 447, 27 (2007). f. R. Kusaka and T. Ebata, Angew. Chem. Int. Ed. 49, 698 (2010). g. R. Kusaka, Y. Inokuchi and T. Ebata, J. Chem. Phys. 136, 044304 (2012).

20. a. N. J. Turro, V. Ramamurthy and J. C. Scaiano, Modern Moleular Photochemistry of Organic Molecules, (University Science Books, Sausalito, 2010). b. M. Klessinger and J. Michl, Excited States and Photochemistry of Organic Molecules, (VCH, Cambridge, UK, 1995).

21. K. A. Holbrook, M. J. Pilling and S. H. Robertson, Unimolecular Reactions, (J. Wiley and Sons, N.Y.C., 1996).

22. a. M. R. Nimios, M. A. Young, E. R. Bernstein and D. F. Kelley, J. Chem. Phys. 91, 5268 (1989). b. E. R. Bernstein, J. Phys. Chem. 96, 10105 (1992). c. M. F. Hineman, S. K. Kim, E. R. Bernstein and D. F. Kelley, J. Chem. Phys. 96, 4904 (1992). d. M. F. Hineman, D. F. Kelley and E. R. Bernstein, J. Chem. Phys. 99, 4533 (1993). e. Q.-Y. Shang, P. O. Moreno, C. Dion and E. R. Bernstein, J. Chem. Phys. 986769 (1993). f. M. Hineman, E. R. Bernstein and D. F. Kelley, J. Chem. Phys. 101, 850 (1994).

23. Q.-Y. Shang and E. R. Bernstein, J. Chem. Phys. 97, 60 (1992).

24. a. S. K. Kim, S. C. Hsu, S. Li and E. R. Bernstein, J. Chem. Phys. 95, 3290 (1991). b. S. K. Kim, S. Li and E. R. Bernstein, J. Chem. Phys. 95, 3119 (1991). c. E. R. Bernstein, J. Chem. Phys. 96, 10105 (1992). d. M. F. Hineman, G. A. Bruker, D. F. Kelley and E. R. Bernstein, J. Chem. Phys. 97, 3341 (1992). e. M. F. Hineman, D. F. Kelley and E. R. Bernstein, J. Chem. Phys.99, 4533 (1993).

25. a. K. Sakota, Y. Kageura and H. Sekiya, J. Chem. Phys. 129, 054303 (2008). b. K. Sakota, Y. Komoto, M. Nakagaki, W. Ishikawa and H. Sekiya, Chem. Phys. Lett. 435, 1 (2007). c. K. Sakota, C. Okabe, N. Nishi and H. Sekiya, J. Phys. Chem. A 109, 5245 (2005). d. G. A. Pino, I. Alata, C. Dedonder, C. Jouvet, K. Sakota and H. Sekiya, J. Phys. Chem. Chem. Phys. 13, 6325 (2011). e. C. Jouvet, D. Solgadi, in Chemical Reactions in Clusters, Ed. E. R. Bernstein, (Oxford, N.Y.C., 1996), p100ff. 
26. a. N. Tsuji, S. Ishiuchi, M. Sakai, M. Fujii, T. Ebata, C. Jouvet and C. Dedoneder-Lardeux, Phys. Chem. Chem. Phys. 8, 114 (2006). b. C. Tanner, C. Manca and S. Leutwyler, J. Chem. Phys. 122, 204326 (2005). c. N. Tsuji, S. Ishiuchi, C. Jouvet, C. Dedoner-Lardeux, M. Miyazaki, M. Sakai and M. Fujii, Chem. Phys. Chem. 12, 1928 (2011). d. Y. Koizumi, C. Jouvet, T. Norihiro, S. Ishiuchi, C. Dedonder-Lardeux and M. Fujii, J. Chem. Phys. 129, 104311 (2008).

27. R. Disselkamp and E. R. Bernstein, J. Phys. Chem. 98, 7260 (1994).

28. a. Y. J. Hu and E. R. Bernstein, J. Chem. Phys. 128, 164311 (2008). b. Y. J. Hu and E. R. Bernstein, J. Phys. Chem. A 113, 8454 (2009). c. J.-W. Shin, F. Dong, M. E. Grisham, J. J. Rocca and E. R. Bernstein, Chem. Phys. Lett. 506, 161 (2011). d. Y. J. Hu, G. Guan and E. R. Bernstein, Mass Spectrom. Rev. 32, 484 (2013).

29. a. S. Hinebuch, F. Dong, J. J. Rocca and E. R. Bernstein, J. Chem. Phys. 125, 154316 (2006). b. F. Dong, S. Hinebuch, J. J. Rocca and E. R. Bernstein, J. Chem. Phys. 125, 154317 (2006). c. F. Dong, S. Hinebuch, J. J. Rocca and E. R. Bernstein, J. Chem. Phys. 124, 224319 (2006). d. S. Hinebuch, F. Dong, J. J. Rocca and E. R. Bernstein, J. Chem. Phys. 126, 244301 (2007). e. C.-Y Ng, Ann. Rev. Phys. Chem. 53, 101 (2002). f. P. A. Hinemann, M. Koike, C. W. Hsu, D. Blank, X. M. Yang, A. G. Suits, Y. T. Lee, M. Evans, C. Y. Ng, C. Flaim and H. A. Padmore, Rev. Sci. Instrum. 68, 1945 (1997). g. T. Zhang, X. N. Tang, K.-C. Lau, C. Y. Ng, C. Nicols, D. S. Peterka, M. Ahmed, M. L. Morton, B. Ruscic, R. Yang, L. X. Wei, C. Q. Huang, B. Yang, J. Wang, L. S. Sheng, Y. W. Zhang and F. Qi, J. Chem. Phys. 124, 074302 (2006).

30. D. W. Boo, Y. Ozaki, L. H. Andersen and W. C. Lineberger, J. Chem. Phys. A 101, 6688 (1997). b. F. Muntean, M. S. Taylor A. B. McCoy and W. C. Lineberger, J. Chem. Phys. 121, 5676 (2004). c. M. S. Taylor, J. Barbera, C.-P. Schulz, F. Muntean, A. B. McCoy and W. C. Lineberger, J. Chem. Phys. 122, 054310 (2005).

31. a. M. J. J. Vrakking, Phys. Chem. Chem. Phys. 16, 2775 (2014). b. A. H. Zewail, Femtochemistry I and II, (World Scientific Pub., Singapore 1994).

32. a. T. G. Dietz, M. A. Duncan, D. E. Powers and R. E. Smalley, J. Chem. Phys. 74, 6511 (1981). b. Atomic and Molecular Clusters, Ed. E. R. Bernstein (Elsevier, Amsterdam, 1990), Chapter 1, R. E. Smalley, and Chapter 2, M. L. Mandich, W. D. Reents and V.E. Bondybey.

33. M. Foltin, G. J. Stueber and E. R. Bernstein, J. Chem. Phys. 111, 9577 (1999). b. M. Foltin, G. J. Stueber and E. R. Bernstein, J. Chem. Phys. 114, 8971 (2001). c. Y. Matsudea, D. N. Shin and E. R. Bernstein, J. Chem. Phys. 1204142 (2004). d. Y. Matsuda, D. N. Shin and E. R. Bernstein, J. Chem. Phys. 120, 4165 (2004). e. D. N. Shin, Y. Matsuda and E. R. Bernstein, J. Chem. Phys. 120, 4157 (2004). f. D. N. Shin, Y. Matsuda and E. R. Bernstein, J. Chem. Phys. 120, 4150 (2004). g. E. R. Bernstein and Y. Matsuda, V. Grassian, Ed. Dekker, N.Y.C., 2005). h. Y. Matsuda and E. R. Bernstein, J. Phys. Chem. A 109, 3803 (2005). i. Y. Matsuda, D. N. Shin and E. R. Bernstein, J. Phys. Chem. A 109, 314 (2005). j. F. Dong, S. Heinbuch, S. G. He, Y. Xie, J. J. Rocca and E. R. Bernstein, J. Chem. Phys. 125, 164318 (2006). k. S. Yin and E. R. Bernstein, Int. J. Mass Spectrom. 49, 321 (2012).

34. a. E. A. Rohlfing, D. M. Cox and A. Kaldor, Chem. Phys. Lett. 99, 161 (1983). b. A. W. Castleman, Jr. and K. H. Bowen, Jr., J. Phys. Chem. 100, 12911 (1996). c. G. C. Nieman, E. K. Parks, S. C. Richtsmeier, K. Liu, L. G. Pobo and S. J. Riley, High Temp. Science 22, 115 (1986). d. E. K. Parks, K. P. Kerns and S. J. Riley, Chem. Phys. 262, 151 (2000). e. E. K. Parks, B. H. Weiller, P. S. Bechthold, W. F. Hoffman, G. C. Nieman, L. G. Pobo and S. J. Riley, J. Chem. Phys. 881622 (1988). f. G. M. Koretsky, K. P. Kerns, G. C. Nieman, M. B. Knickelbein and S. J. Riley, J. Phys. Chem. 103, 1997 (1999). g. J. D. K. Salahub, N. Russo (Eds), Metal-Ligand Interactions: from Atoms to Clusters, to Surfaces, (Kluwer Acad. Pub., Amsterdam, 1992), S. J. 
Riley, p. 17. h. M. B. Knickelbein, Philosophical Magazine 79, 1379 (1999). i. E. K. Parks, B. J. Winter, T. D. Klots and S. J. Riley, J. Chem. Phys. 94, 1882 (1991). j. G. C. Nieman, E. K. Parks, S. C. Richtsmeier, K. Liu, L. G. Pobo and S. J. Riley, High Temperature Science 22, 115 (1986). k. K. A. Jackson, M. B. Knickelbein, G. Koretsky and S. Srinivas, Chem. Phys. 1.5, 1 (2000). 1. M. B. Knickelbein, G. M. Koretsky, K. A. Jackson, M. R. Pederson and Z. Hajnal, J. Chem. Phys. 109, 10692 (1998).

35. a. E. Jakubikova, A. K. Rappé and E. R. Bernstein, J. Phys. Chem. A 110, 9529 (2006). b. E. Jakubikova, A. K. Rappé, and E. R. Bernstein, J. Phys. Chem. A 111, 12938 (2007). c. E. Jakubikova and E. R. Bernstein, J. Phys. Chem. A 111, 13339 (2007).

36. a. F. Dong, S. Heinbuch, Y, Xie, J. J. Rocca and E. R. Bernstein, Phys. Chem. Chem. Phys.12, 2569 (2010). b. F. Dong, Y. Xie and E. R. Bernstein, J. Phys. Chem. A 135, 054307 (2011).

37. a. S. Yin and E. R. Bernstein, Int. J. Mass Spectrom. 49, 321 (2012). b. Environmental Catalysis, Ed. V. H. Grassian, (Taylor \& Francis, N.Y.C., 2005), Chapter 17, E. R. Bernstein, Y. Matsuda, p. 421. c. Encyclopedia of Mass Spectrometry, V. Ed. D. Beauchemin, D. E. Mathews, (Elsevier, Amsterdam, 2010), Chapter 6, Y. Xie, E. R. Bernstein, p. 557.

38. S.-G. He, Y. Xie, F. Dong, S. Heinbuch, E. Jakubikova, J. J. Rocca and E. R. Bernstein, J. Phys. Chem. A 11211067 (2008).

39. F. Dong, S. Heinbuch, Y. Xie, J. J. Rocca and E. R. Bernstein, J. Am. Chem. Soc. 130, 1932 (2008).

40. a. Z.-C. Wang, W. Xue, Y.-P. Ma, X.-L. Ding, S.-G. He, F. Dong, S. Heinbuch, J. J. Rocca and E. R. Bernstein, J. Phys. Chem A 112, 5984 (2008). b. F. Dong, S. Heinbuch, Y. Xie, J. J. Rocca and E. R. Bernstein, J. Am. Chem. Soc.131, 1057 (2009). c. F. Dong, S. Heinbuch, Y. Xie, J. J. Rocca and E. R. Bernstein, J. Phys. Chem. A 113, 3029 (2009). d. S. Heinbuch, F. Dong, J. J. Rocca and E. R. Bernstein, J. Chem. Phys. 133, 174314 (2010).

41. Z. C. Wang, S. Yin and E. R. Bernstein, Phys. Chem. Chem. Phys. 15, 10429 (2013).

42. Y. Xie, S. G. He and E. R. Bernstein, J. Chem. Phys. 128, 044306 (2008).

43. S. Yin, Y. Xie and E. R. Bernstein, J. Phys. Chem. A 115, 10266 (2011).

44. S. Yin, Z. C. Wang and E. R. Bernstein, Phys. Chem. Chem. Phys. 15, 4699 (2013).

45. Y. Xie, F. Dong and E. R. Bernstein, Catal. Today 177, 64 (2011).

46. S. Yin, Y. Xie and E. R. Bernstein, J. Chem. Phys. 137, 124304 (2012).

47. S. Yin, Z. C. Wang and E. R. Bernstein, J. Chem. Phys. 139, 084307 (2013).

48. Z. C. Wang, S. Yin and E. R. Bernstein, J. Phys. Chem. Lett. 3, 2415 (2012).

49. Z. C. Wang, S. Yin and E. R. Bernstein, Phys. Chem. Chem. Phys. 15, 10429 (2013).

50. S. Yin and E. R. Bernstein, Phys. Chem. Chem. Phys. 16, 13900 (2014).

51. Z. C. Wang, S. Yin and E. R. Bernstein, J. Chem. Phys. 139, 194313 (2013).

52. H.-J. Zhai, Y.-F. Zhao, W.-L. Li, Q. Chen, H. Bai, H.-S. Hu, Z. A. Piazza, W.-J. Tian, H.-G. Lu, Y.-B. Wu, Y.-W. Mu, G.-F. Wei, Z.-P. Liu, J. Li, S.-D. Li, and L.-S. Wang, Nasture (Chemistry) 6, 727 (2014). 


\section{Figures and captions}
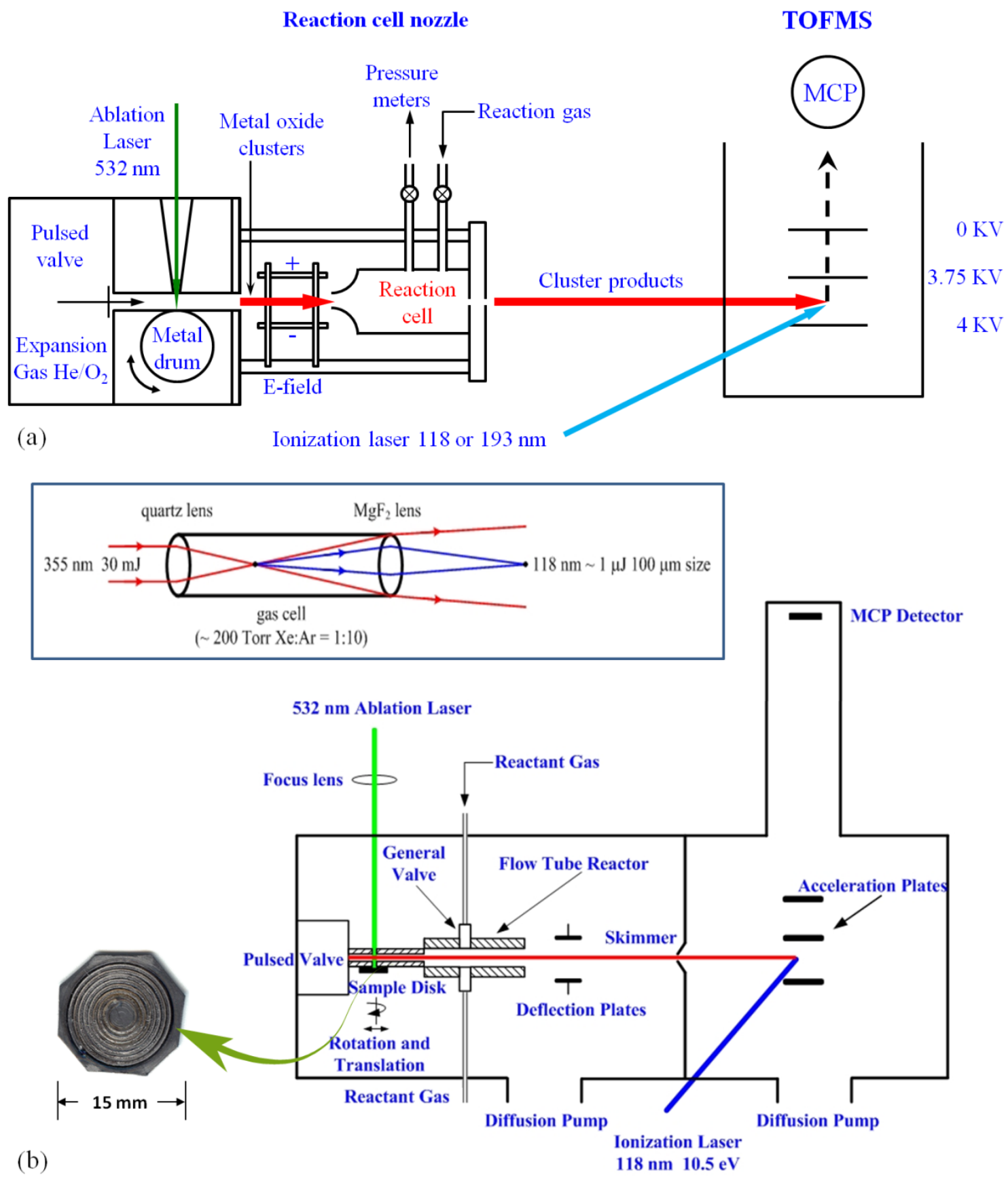

Figure 1. (a) Schematic drawing of a low-pressure ( $<1$ Torr $)$ high-temperature $(\sim 700 \mathrm{~K})$ pickup cell reactor with a metal drum sample in a single chamber. Schematic representation for $118 \mathrm{~nm}$ generation. (b) Schematic drawing of a high-pressure (1-50 Torr) low-temperature $(\sim 300 \mathrm{~K})$ fast-flow reactor with a metal disk target in a differential chamber (MCP: microchannel plate). 


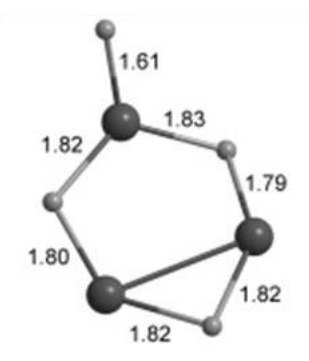

$\mathrm{V}_{3} \mathrm{O}_{4}$ ${ }^{2} \mathrm{~A}: \mathrm{C}_{1}$

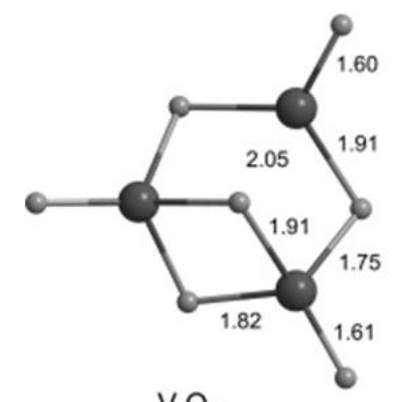

$\mathrm{V}_{3} \mathrm{O}_{7}$

${ }^{2} \mathrm{~A} ; \mathrm{C}_{1}$

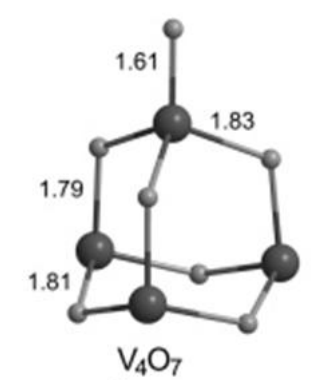

${ }^{7} \mathrm{~A} ; \mathrm{C}_{1}$

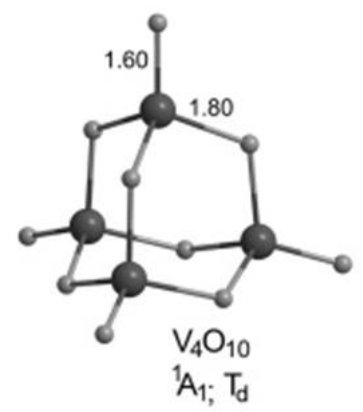

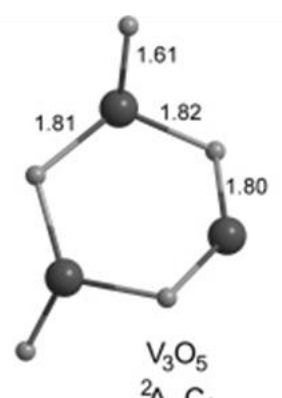

${ }^{2} \mathrm{~A} ; \mathrm{C}_{1}$

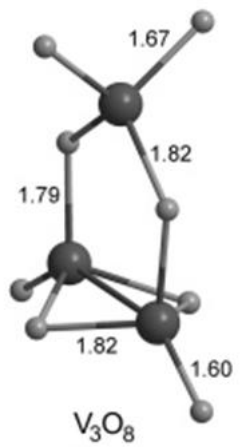

'2A'; $C_{S}$

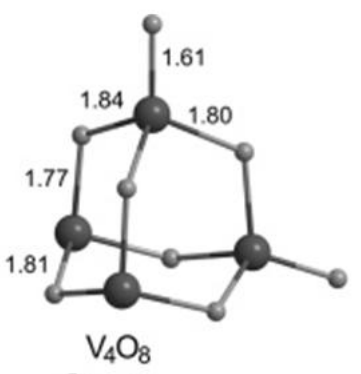

${ }^{5} \mathrm{~B}_{2} ; \mathrm{C}_{2 \mathrm{~V}}$

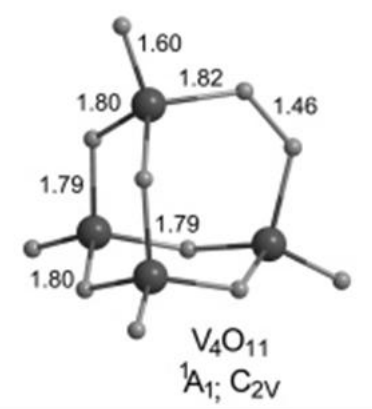

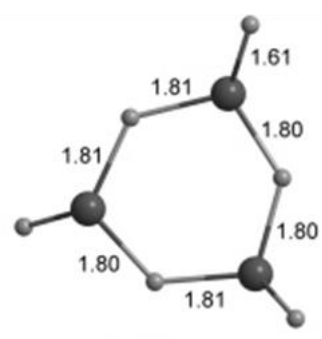

$\mathrm{V}_{3} \mathrm{O}_{6}$

${ }^{2} \mathrm{~A} ; \mathrm{C}_{1}$

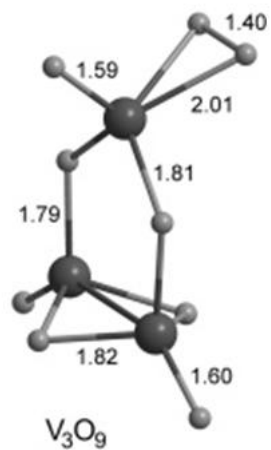

2A"; CS

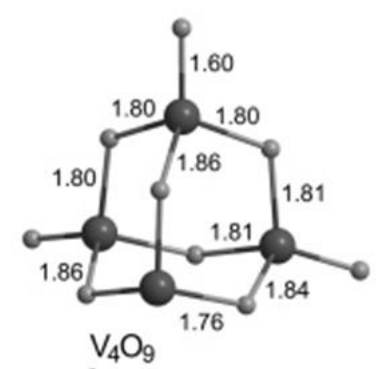

${ }^{3} \mathrm{~A} ; \mathrm{C}_{1}$

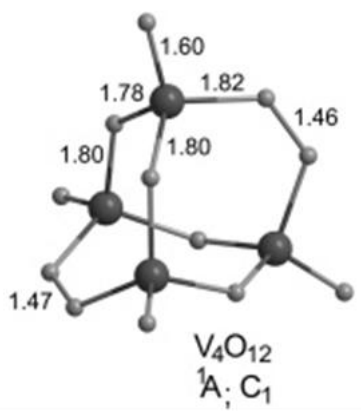

Figure 2. Lowest energy structures of $\mathrm{V}_{3} \mathrm{O}_{y}(y=4-9)$ and $\mathrm{V}_{4} \mathrm{O}_{y}(y=7-12)$ clusters. 


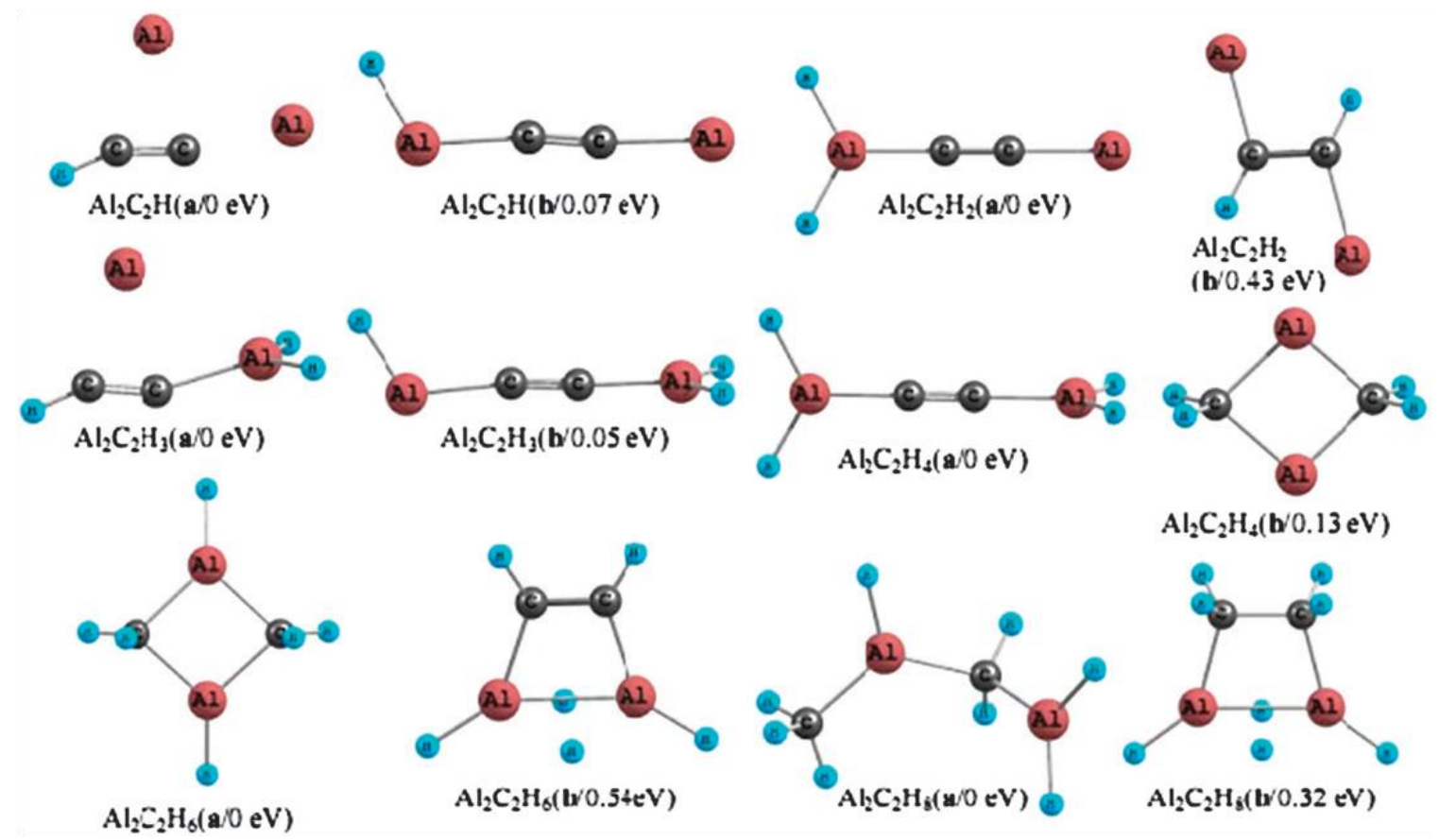

Figure 3. Optimized geometries for various $\mathrm{Al}_{2} \mathrm{C}_{2} \mathrm{H}_{x}$ clusters at the B3LYP/6-311+G* theory level. The isomer (a) and (b) are two lowest energy structures. Values (in eV) in parentheses below each geometry are the isomer energies relative to lowest energy isomer a. 

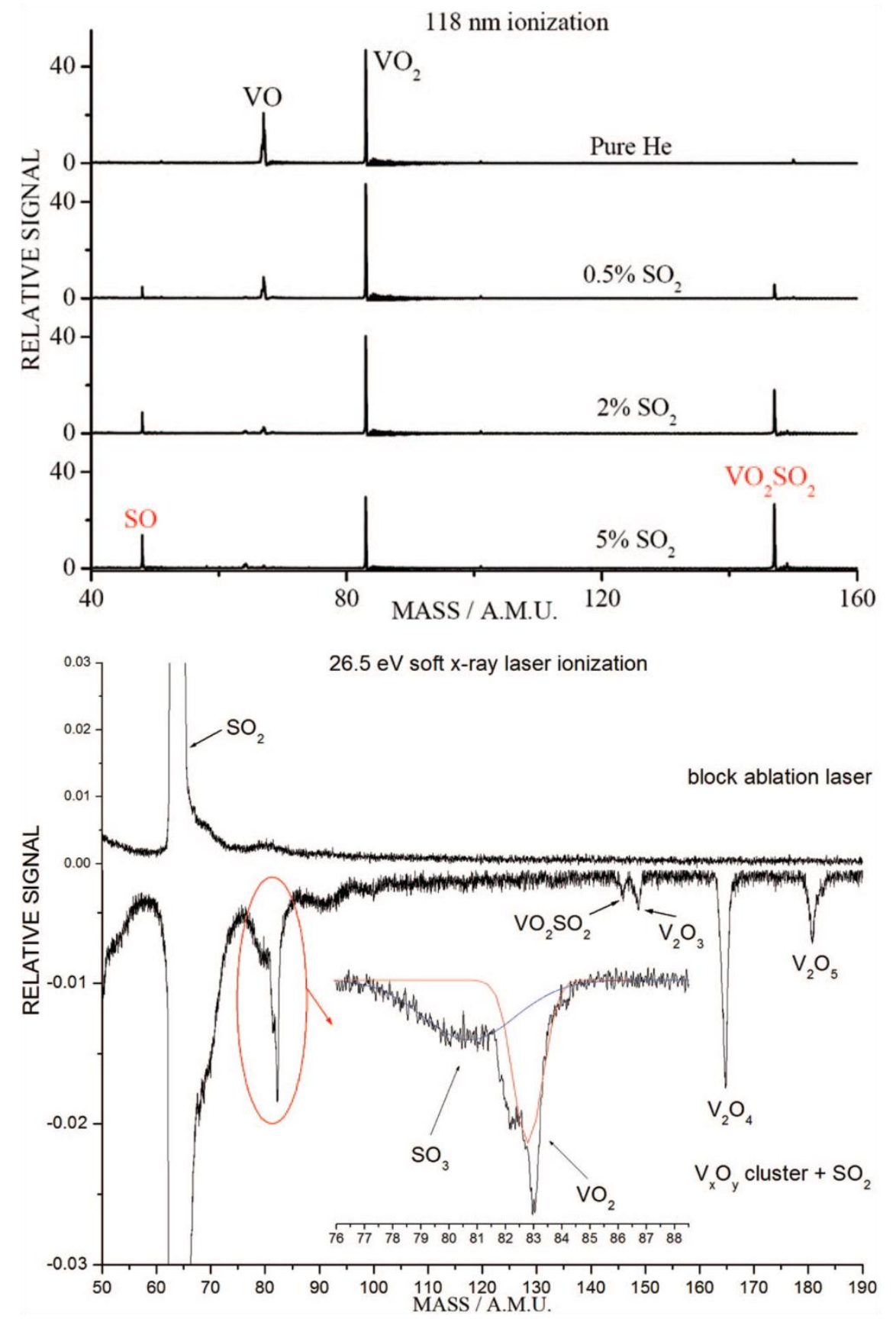

Figure 4. TOF mass spectra (low-mass region) for reactions of $\mathrm{V}_{m} \mathrm{O}_{n}$ with different concentrations of $\mathrm{SO}_{2}$ seeded in $\mathrm{He}$. The concentrations of $\mathrm{SO}_{2}$ are $0,0.5,2$, and $5 \%$ from top to bottom traces. $1 \% \mathrm{O}_{2}$ seeded in He is used to produce $\mathrm{V}_{m} \mathrm{O}_{n}$ (this condition is kept to obtain all the TOF spectra reported in the present work); TOF mass spectra for reaction of $\mathrm{V}_{m} \mathrm{O}_{n}$ with $\mathrm{SO}_{2}$ employing a $26.5 \mathrm{eV}$ soft $\mathrm{X}$-ray laser for ionization. A product $\mathrm{SO}_{3}$ is observed when $\mathrm{SO}_{2}$ is added (bottom trace), and it disappears with the $\mathrm{V}_{m} \mathrm{O}_{n}$ cluster signal when the ablation laser is blocked (top trace). 


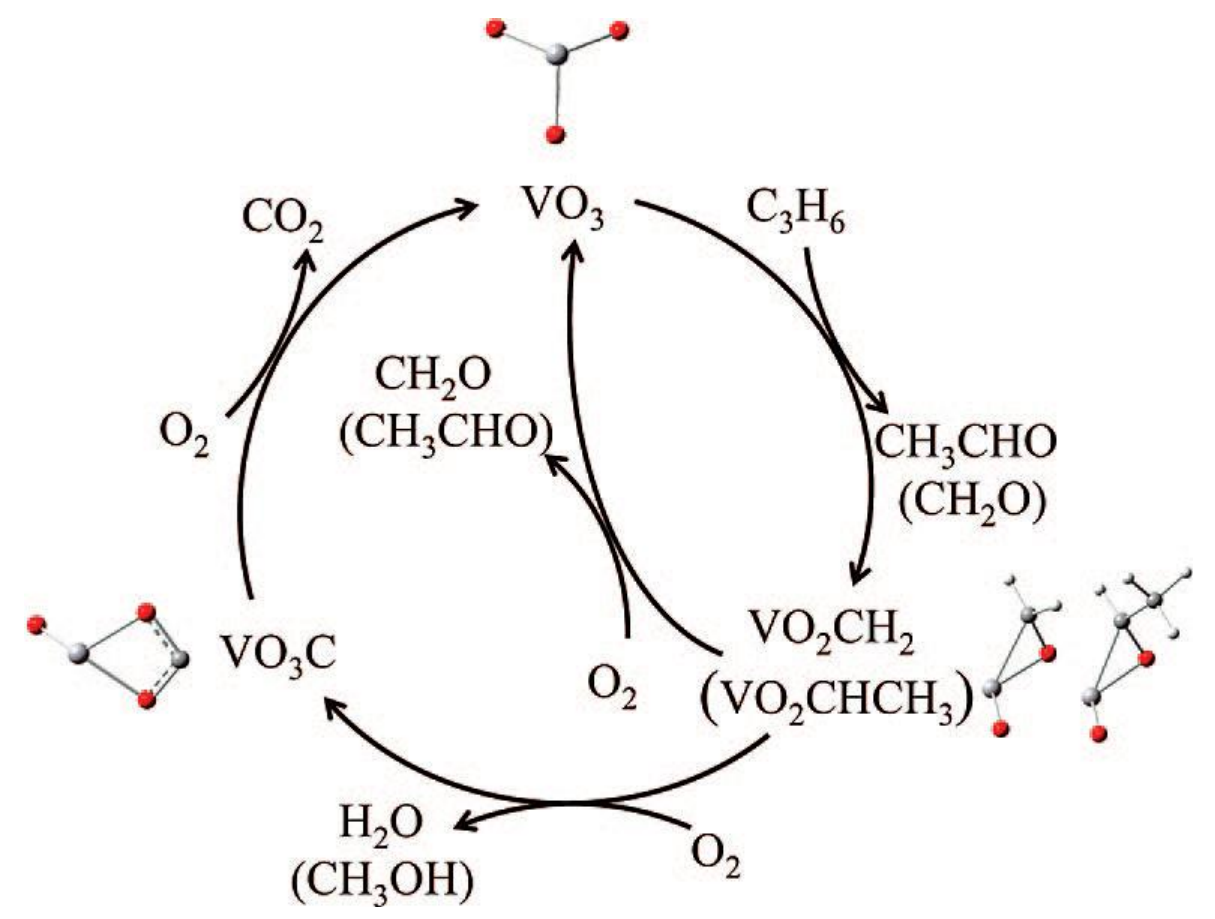

Figure 5. Schematic diagram showing barrierless reaction channels that form catalytic cycles for propylene $\left(\mathrm{C}_{3} \mathrm{H}_{6}\right)$ partial oxidation over the $\mathrm{VO}_{3}$ cluster under gas phase, room temperature conditions. 

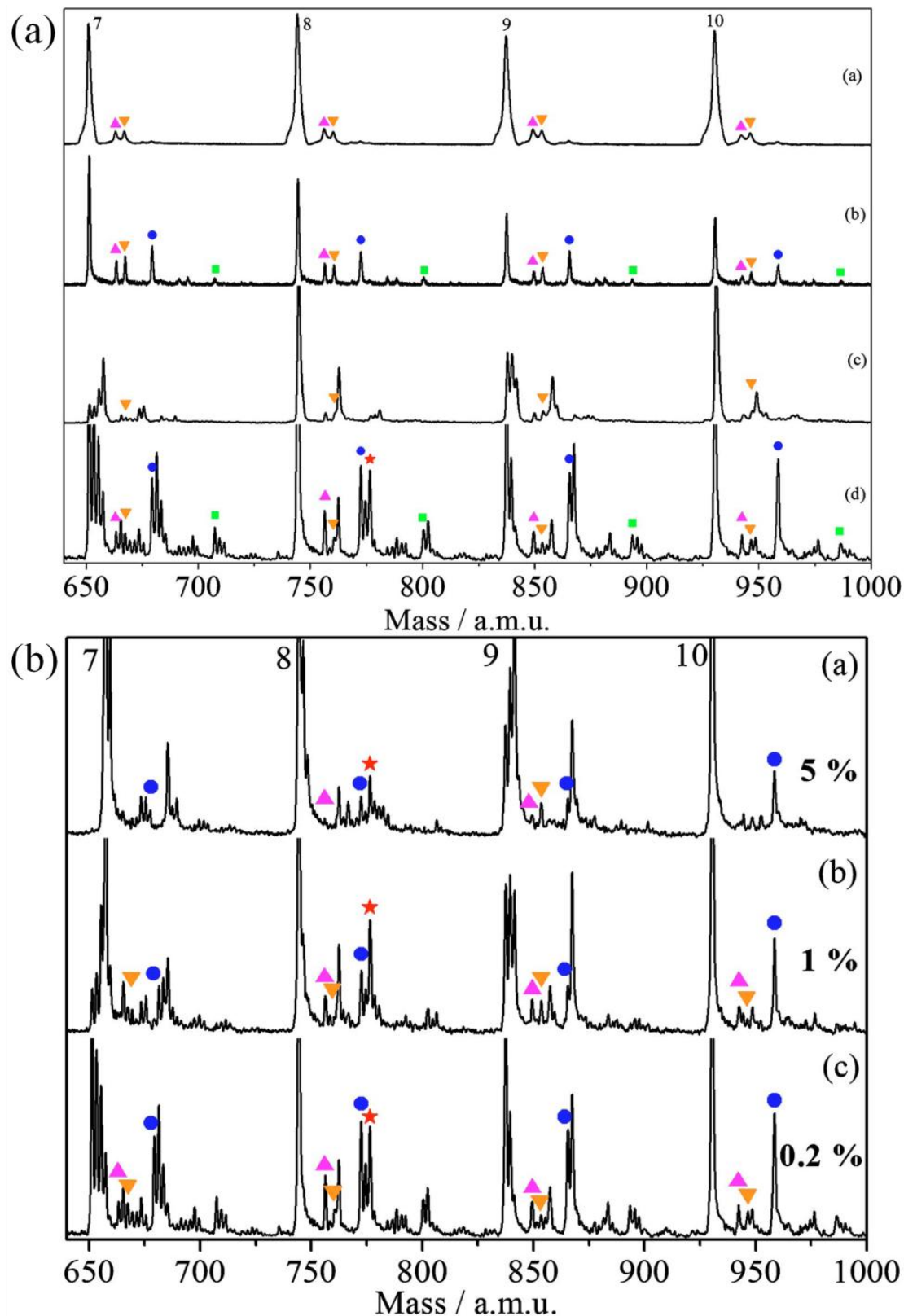

Figure 6. (a) Product distribution for bare $\mathrm{Nb}_{n}(n=7-10)$ metal clusters (a), the reactions of $\mathrm{Nb}_{n}(n=7-10)$ with $50 \mathrm{ppm} \mathrm{CO}(\mathrm{b}), 1.5 \% \mathrm{H}_{2}(\mathrm{c})$, and $92 \mathrm{ppm} \mathrm{CO}+0.2 \% \mathrm{H}_{2}(\mathrm{~d})$ in a flow tube reactor. Ionization is by a $193 \mathrm{~nm}$ laser at a fluence of $200 \mu \mathrm{J} / \mathrm{cm}^{2}$; (b) Product distribution for the reaction of $\mathrm{Nb}_{n}(n=7-10)$ with $92 \mathrm{ppm} \mathrm{CO}$ and $5 \%$ (a), 1\% (b), and $0.2 \%$ (c) $\mathrm{H}_{2}$ in a flow tube reactor. Ionization is by a $193 \mathrm{~nm}$ laser at a fluence of $200 \mu \mathrm{J} / \mathrm{cm}^{2}$. Note that the relative intensities of $\mathrm{Nb}_{7} \mathrm{COH}_{2 k}$ and $\mathrm{Nb}_{9} \mathrm{COH}_{2 k}(k=1,2,3, \ldots)$ change as the hydrogen concentration is varied, while this is not the case for $\mathrm{Nb}_{8} \mathrm{COH}_{2 k} \mathbf{\bullet}, \mathbf{\nabla}, \bullet, \mathbf{\bullet}$, and $\star$ indicate carbide impurities, oxide impurities, $\mathrm{Nb}_{n} \mathrm{CO}, \mathrm{Nb}_{n}(\mathrm{CO})_{2}$, and $\mathrm{Nb}_{n} \mathrm{COH}_{4}$, 
respectively. Additionally, hydrogen adsorbs on $\mathrm{Nb}_{7,9}$ clusters more readily than on $\mathrm{Nb}_{8,10}$.
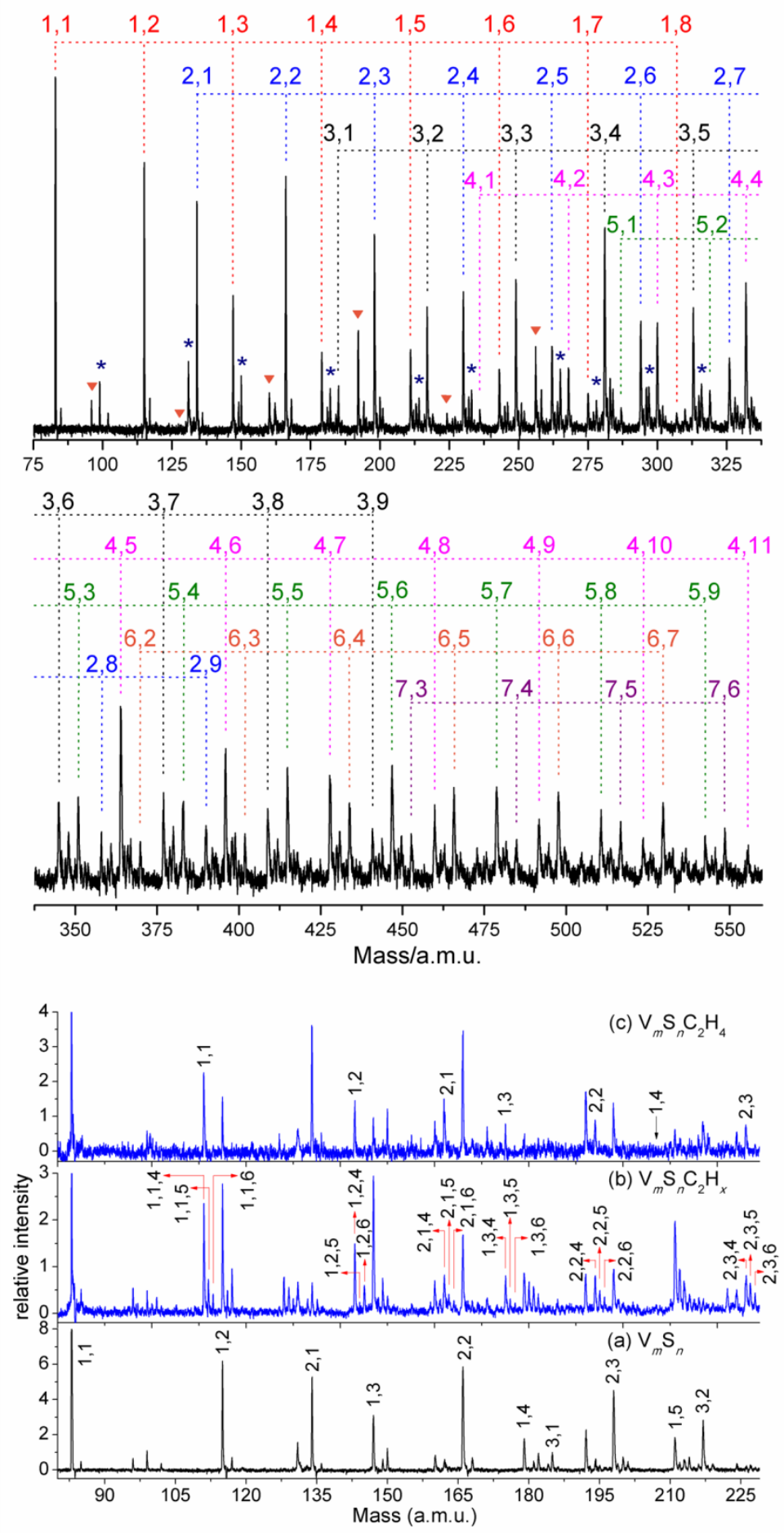

Figure 7. Neutral vanadium sulfide cluster $\mathrm{V}_{m} \mathrm{~S}_{n}(m=1-7, n=1-11)$ distribution detected by $118 \mathrm{~nm}$ single photon ionization and time of flight mass spectrometry. The series of pure sulfur clusters $S_{m}(m=3-8)$ are marked by a down triangle symbol, and the peaks marked with a star symbol are due to oxygen impurities; and neutral vanadium sulfide cluster $\mathrm{V}_{m} \mathrm{~S}_{n}(m=1,2 ; n=1-5)$ distributions after reaction and collision with (a) pure 
helium; (b) $5 \% \mathrm{C}_{2} \mathrm{H}_{4} / \mathrm{H}_{2}$; (c) $5 \% \mathrm{C}_{2} \mathrm{H}_{4} / \mathrm{He}$ in a fast flow reactor.
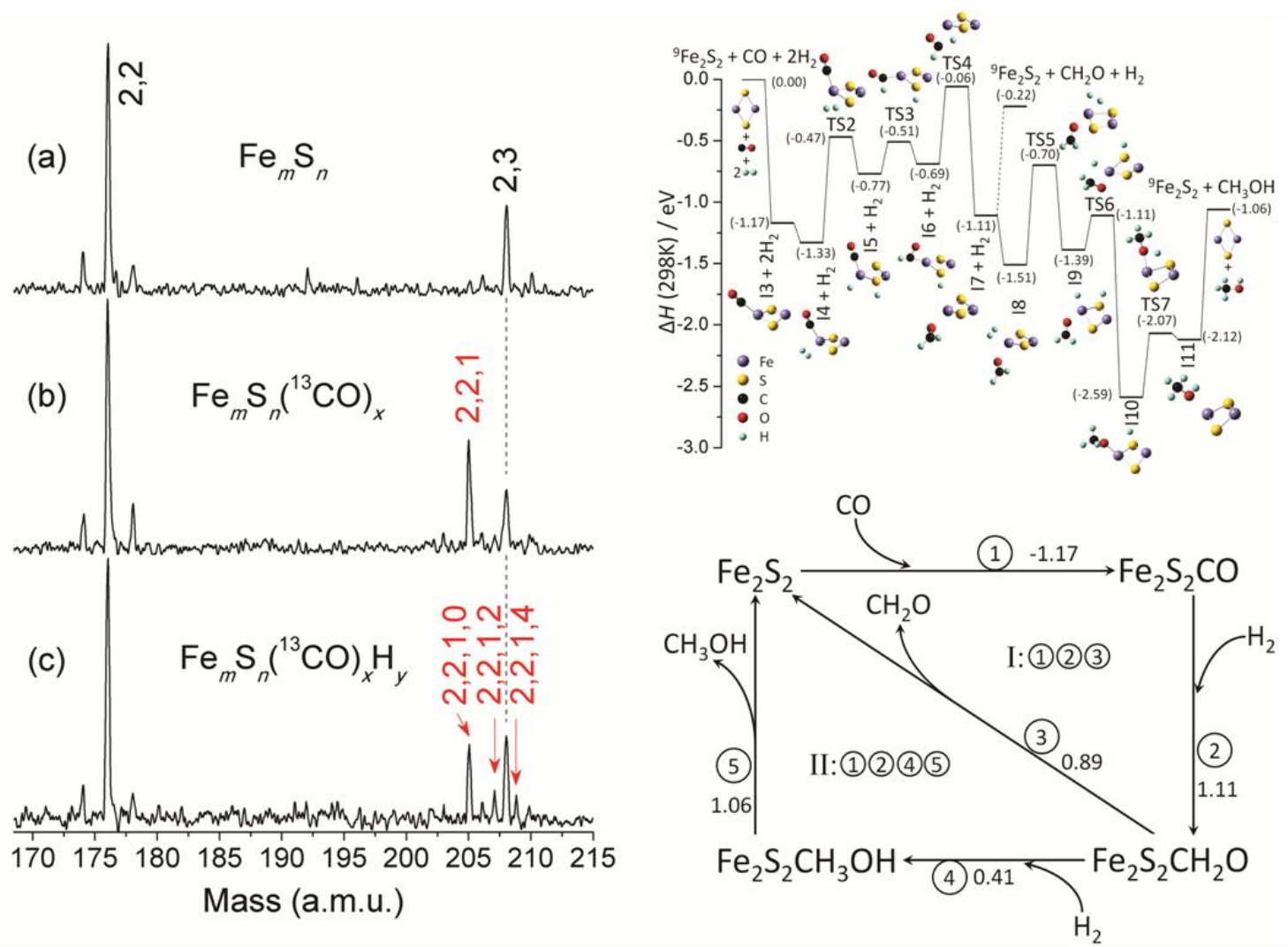

Figure 8. Product distribution for the reaction of neutral $\mathrm{Fe}_{2} \mathrm{~S}_{2}$ clusters with (a) pure helium, (b) $20 \%{ }^{13} \mathrm{CO} / \mathrm{He}$, and (c) $20 \%{ }^{13} \mathrm{CO} / \mathrm{H}_{2}$, in a fast flow reactor. Products are labeled as $\mathrm{Fe}_{m} \mathrm{~S}_{n}\left({ }^{13} \mathrm{CO}\right)_{x} \mathrm{H}_{y}(m, n, x, y)$; a potential energy surface profile for the reaction ${ }^{9} \mathrm{Fe}_{2} \mathrm{~S}_{2}+$ $\mathrm{CO}+2 \mathrm{H}_{2} \rightarrow{ }^{9} \mathrm{Fe}_{2} \mathrm{~S}_{2}+\mathrm{CH}_{3} \mathrm{OH}$. Energies are in $\mathrm{eV}$ and relative to the initial reactant energy of ${ }^{9} \mathrm{Fe}_{2} \mathrm{~S}_{2}+\mathrm{CO}+2 \mathrm{H}_{2}$. Energy levels are calculated by B3LYP/SVP. The spin multiplicity $(M)$ is listed as ${ }^{M} \mathrm{Fe}_{2} \mathrm{~S}_{2}$. The release of formaldehyde from I7 and methanol from I11 require $0.89 \mathrm{eV}$ and $1.06 \mathrm{eV}$ energies, respectively; and catalytic cycles for formaldehyde and methanol formation from reaction of carbon monoxide and hydrogen over neutral $\mathrm{Fe}_{2} \mathrm{~S}_{2}$ clusters in the gas phase. The overall reaction barriers $\left(\Delta H_{\mathrm{ORB}}\right)$ in $\mathrm{eV}$ for each elementary step are given. 


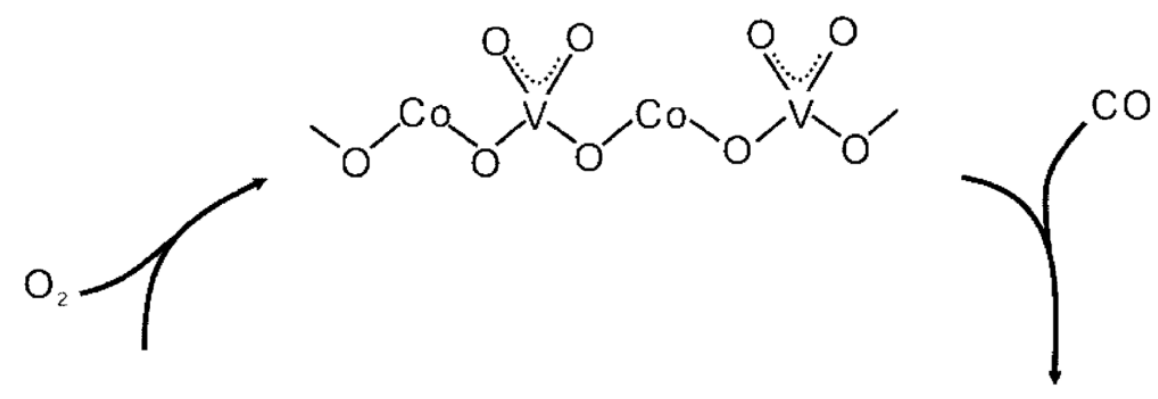<smiles>COCOO[Y](=O)OCOO[Al](=O)OC</smiles>

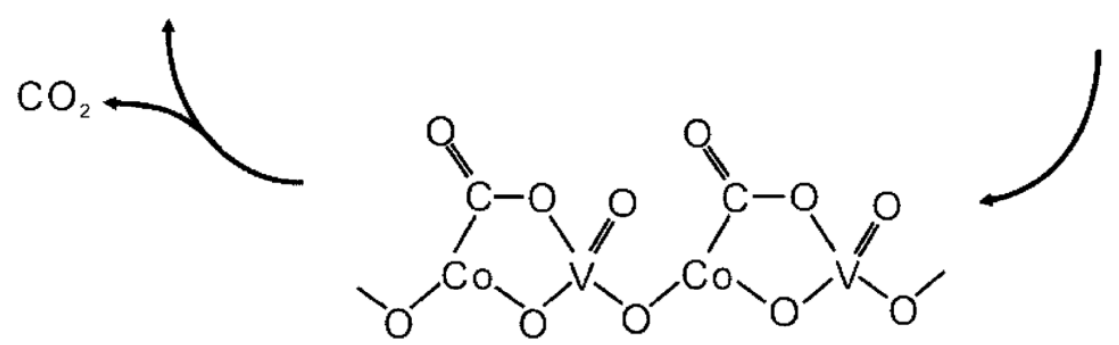

Figure 9. Proposed full catalytic cycle for $\mathrm{CO}$ oxidation to $\mathrm{CO}_{2}$ on a $\mathrm{V}-\mathrm{Co}$ oxide surface based on the calculations for the reaction of $\mathrm{VCoO}_{4}$ cluster with $\mathrm{CO}$. 

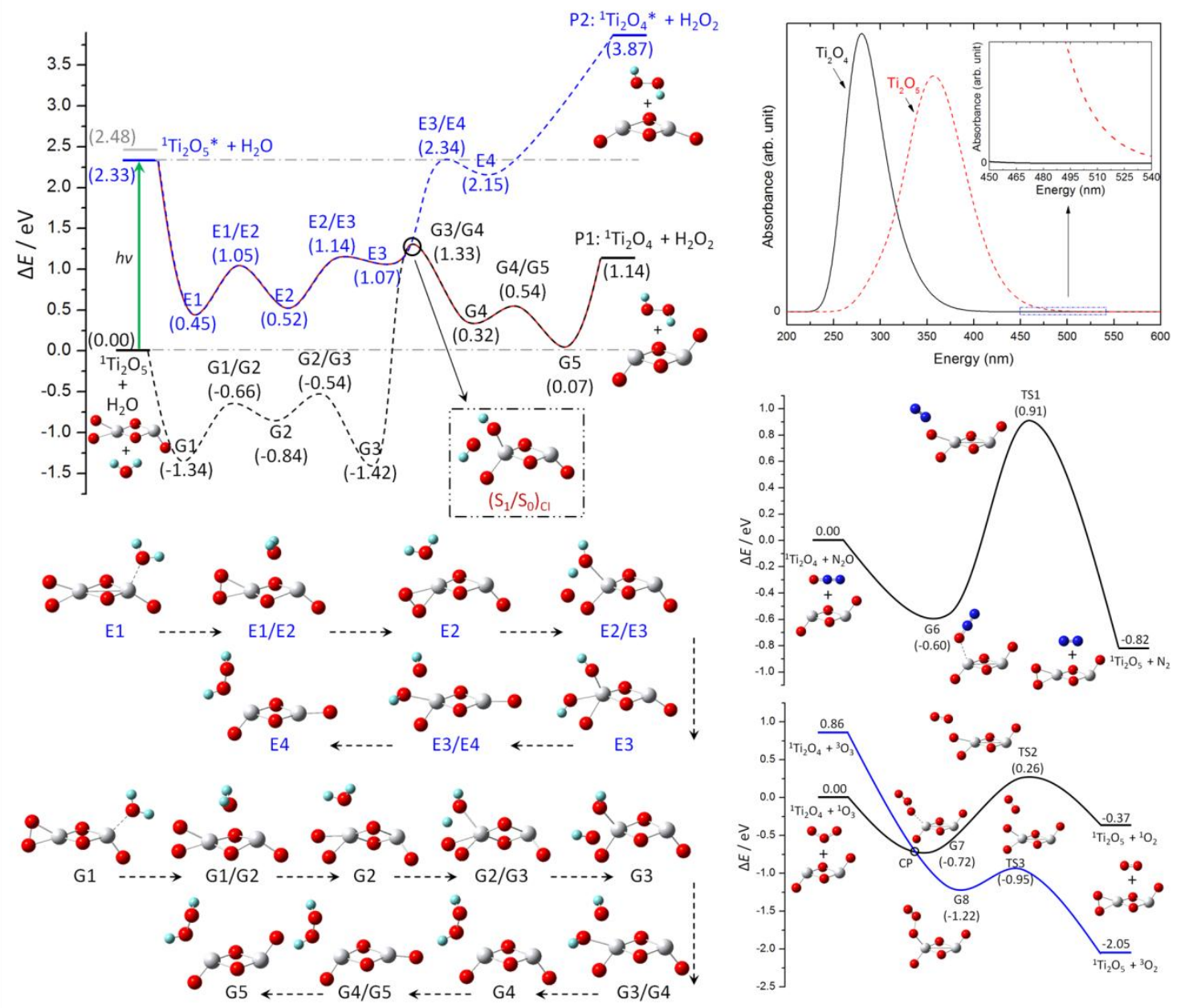

Figure 10. A potential energy surface profile of ground and first singlet excited states for the reaction $\mathrm{Ti}_{2} \mathrm{O}_{5}+\mathrm{H}_{2} \mathrm{O} \rightarrow \mathrm{Ti}_{2} \mathrm{O}_{4}+\mathrm{H}_{2} \mathrm{O}_{2}$. Energies are in $\mathrm{eV}$, relative to the initial reactant energy of ${ }^{1} \mathrm{Ti}_{2} \mathrm{O}_{5}+\mathrm{H}_{2} \mathrm{O}$. Energy levels are calculated at the B3LYP/TZVP theory level. The spin multiplicity $(M)$ is listed as ${ }^{M} \mathrm{Ti}_{2} \mathrm{O}_{4,5}$ " $"\left(\mathrm{~S}_{1} / \mathrm{S}_{0}\right)_{\mathrm{Cl}}$ " denotes a conical intersection for the ground and excited state potential energy surfaces. Geometry of the $\left(\mathrm{S}_{1} / \mathrm{S}_{0}\right)_{\mathrm{CI}}$ is calculated at the $\operatorname{CASSCF}(10,7) / 6-31 \mathrm{~g}(\mathrm{~d})$ level; optical spectra of gas phase neutral $\mathrm{Ti}_{2} \mathrm{O}_{4}$ (black) and $\mathrm{Ti}_{2} \mathrm{O}_{5}$ (red) clusters using TDDFT calculations; and Potential energy surface profiles of the ground state for reactions $\mathrm{Ti}_{2} \mathrm{O}_{4}+\mathrm{N}_{2} \mathrm{O} \rightarrow \mathrm{Ti}_{2} \mathrm{O}_{5}+\mathrm{N}_{2}$ and $\mathrm{Ti}_{2} \mathrm{O}_{4}+\mathrm{O}_{3} \rightarrow \mathrm{Ti}_{2} \mathrm{O}_{5}+\mathrm{O}_{2}$. Energies are in eV, relative to the initial reactant energy. Energy levels are calculated at the B3LYP/TZVP theory level. The spin multiplicity $(M)$ is listed as ${ }^{M} \mathrm{Ti}_{2} \mathrm{O}_{4,5},{ }^{M} \mathrm{O}_{2}$, and ${ }^{M} \mathrm{O}_{3}$. "CP" denotes a possible spin conversion point for the $\mathrm{O}_{3}$ singlet and triplet potential energy surfaces. 